Article

\title{
Effects of Vanadium/Nickel Contents in Laves Phase-Related Body-Centered-Cubic Solid Solution Metal Hydride Alloys
}

\author{
Kwo-hsiung Young ${ }^{1,2, *}$, Diana F. Wong ${ }^{1,2, \dagger}$ and Jean Nei ${ }^{1, \dagger}$ \\ 1 BASF/Battery Materials-Ovonic, 2983 Waterview Drive, Rochester Hills, MI 48309, USA; \\ E-Mails: diana.f.wong@basf.com (D.F.W.); jean.nei@basf.com (J.N.) \\ 2 Department of Chemical Engineering and Materials Science, Wayne State University, Detroit, \\ MI 48202, USA \\ $\dagger$ These authors contributed equally to this work. \\ * Author to whom correspondence should be addressed; E-Mail: kwo.young@basf.com; \\ Tel.: +1-248-293-7000; Fax: +1-248-299-4520.
}

Academic Editor: Andreas Jossen

Received: 5 October 2015 / Accepted: 16 November 2015 / Published: 20 November 2015

\begin{abstract}
Structural, gaseous phase hydrogen storage, and electrochemical properties of a series of annealed $\left(900{ }^{\circ} \mathrm{C}\right.$ for $12 \mathrm{~h}$ ) Laves phase-related body-centered-cubic (BCC) solid solution metal hydride $(\mathrm{MH})$ alloys with vanadium/nickel (V/Ni) contents ranging from $44 / 18.5$ to $28 / 34.5$ were studied. As the average Ni-content increases, C14 phase evolves into the $\mathrm{C} 15$ phase and a new $\sigma$-VNi phase emerges; lattice constants in BCC, C14, and TiNi phase all decrease; the main plateau pressure increases; both gaseous phase and electrochemical hydrogen storage capacities decrease; the pressure-concentration-temperature (PCT) absorption/desorption hysteresis decreases; both high-rate dischargeability (HRD) and bulk hydrogen diffusivity increase and then decrease; and the surface reaction current decreases. There is a capacity-rate tradeoff with the change in V/Ni content. Alloys with relatively lower Ni-content show higher capacities but inferior high-rate performance compared to commercially available $\mathrm{AB}_{5} \mathrm{MH}$ alloy. Increasing the Ni-content in this BCC-based multi-phase alloy can improve the high-rate capability over $\mathrm{AB}_{5}$ alloy but with lower discharge capacities. The inferior surface reaction current in these alloys, compared to $\mathrm{AB} 5$, may be due to the smaller surface area, not the total volume, of the Ni clusters embedded in the surface oxide layer of the activated alloys.
\end{abstract}


Keywords: hydrogen absorbing alloys; metal hydride (MH) electrode; Laves phase alloys; body-centered-cubic alloys; phase segregation

\section{Introduction}

"Laves phase-related body-centered-cubic (BCC) solid solution" is a family of metal hydride (MH) alloys composed mainly of a BCC phase and a Laves phase (mostly C14), which can be used as the negative electrode active material for nickel/metal hydride $(\mathrm{Ni} / \mathrm{MH})$ batteries $[1,2]$. Other minor phases, such as $\mathrm{C} 15$, TiNi, $\mathrm{Ti}_{2} \mathrm{Ni}$, and VNi can also be included. Both $\mathrm{V}$ and $\mathrm{TiCr}$ intermetallic alloys have the same BCC crystal structure, which enable a wide composition solubility range for BCC phase in the Ti-V-Cr ternary phase diagram [3]. Alloys with sole BCC structure can have a hydrogen storage capacity higher than $3.5 \mathrm{wt} \%$ [4,5], but the electrochemical performance is poor because of severe cracking and passivation on the surface [5]. Adding Ni into the alloy formula promotes the formation of a C14 phase [6]. The introduction of Laves phases promotes good absorption kinetics [7], easy formation due to its brittleness [8-10], and high surface catalytic activity through a synergetic effect [11]. Many works have been reported in this family of alloys that partially replace $\mathrm{Ti}, \mathrm{V}$, and $\mathrm{Cr}$ with other transition metals for improvements in both hydrogen storage [9,12-19] and electrochemical applications [20-23]. Our contributions to the field include the introduction of a high hydrogen pressure activation process [24], an optimization of annealing conditions $\left(900^{\circ} \mathrm{C}\right.$ for $12 \mathrm{~h}$ ) [25], and a study examining the contributions of the constituent elements in Laves phase-related BCC solid solutions. The contributions of the elements are summarized as: removal of $\mathrm{Fe}$ and decrease in $\mathrm{V}$-content in exchange for higher $\mathrm{Ni}$-content to improve both the electrochemical capacity and high-rate dischargeability (HRD); elimination of the $\mathrm{C} 14$ phase by removal of $\mathrm{Zr}$ contributing to a reduced discharge capacity, a prolonged activation period, and a less catalytic surface for electrochemical reaction; and the TiNi phase was also found to contribute positively to the bulk diffusion of hydrogen while hindering the surface electrochemical reaction. In the same study, an alloy (P17) achieved a full capacity of $390.8 \mathrm{mAh} \cdot \mathrm{g}^{-1}$ at a small discharge rate of $4 \mathrm{~mA} \cdot \mathrm{g}^{-1}$; however, the capacity decreases to $365.4 \mathrm{mAh} \cdot \mathrm{g}^{-1}$ when the discharge rate was increased to $50 \mathrm{mAh} \cdot \mathrm{g}^{-1}$ [26]. The capacity degradation with increased rate in P17 is worse than that in the conventional $\mathrm{AB}_{5} \mathrm{MH}$ alloys (from $336 \mathrm{mAh} \cdot \mathrm{g}^{-1}$ to $329 \mathrm{mAh} \cdot \mathrm{g}^{-1}$ ) under the same test condition [27]. The HRD is very important for the high-power applications for Ni/MH battery, such as in hybrid electrical vehicles and power tools. Previously, Ni has been known to increase the HRD of the MH alloys [22,28-32]. In order to further improve the HRD performance, the vanadium/nickel content in alloy P17 was adjusted and the results are presented here.

\section{Experimental Section}

Ingot sample was prepared by an arc-melting, which includes a non-consumable tungsten electrode, a water-cooled copper tray and a continuous argon flow. A piece of sacrificial titanium underwent a few melting-cooling cycles to reduce the residual oxygen concentration in the system before each run. Each $12 \mathrm{~g}$ ingot was re-melted and turned over several times to ensure uniformity in chemical composition. Following previously developed annealing conditions, each ingot was annealed in vacuum at $900{ }^{\circ} \mathrm{C}$ for 
12-h [25]. Chemical compositions for each ingot was analyzed using a Varian Liberty 100 inductively coupled plasma-optical emission spectrometer (ICP-OES, Agilent Technologies, Santa Clara, CA, USA). A Philips X'Pert Pro X-ray diffractometer (XRD, Philips, Amsterdam, Netherlands) was used to study the microstructure, and a JEOL-JSM6320F scanning electron microscope (SEM, JEOL, Tokyo, Japan) with energy dispersive spectroscopy (EDS) capability was used to study the phase distribution and composition. Gaseous phase hydrogen storage characteristics for each sample were measured using a Suzuki-Shokan multi-channel pressure-concentration-temperature (PCT, Suzuki Shokan, Tokyo, Japan) system. In the PCT analysis, each sample (a single piece of ingot with a newly cleaved surface and a weight of about $2 \mathrm{~g}$ ) was first activated by a 2-h thermal cycle (between $300{ }^{\circ} \mathrm{C}$ and $30{ }^{\circ} \mathrm{C}$ ) at $5 \mathrm{MPa} \mathrm{H}_{2}$ pressure. PCT isotherms at 30 and $60{ }^{\circ} \mathrm{C}$ were then measured. Magnetic susceptibility was measured using a Digital Measurement Systems Model 880 vibrating sample magnetometer (MicroSense, Lowell, MA, USA).

\section{Results and Discussion}

\subsection{Alloy Composition}

Eight alloys with a general formula of $\mathrm{Ti}_{15.6} \mathrm{Zr}_{2.1} \mathrm{~V}_{44-x} \mathrm{Cr}_{11.2} \mathrm{Mn}_{6.9} \mathrm{Co}_{1.4} \mathrm{Ni}_{18.5+x} \mathrm{Al}_{0.3}, x=0,4,6,8,10$, 12,14 , and 16, were prepared by arc melting for this study. Design compositions of these alloys are listed in Table 1. Alloys P17 $(x=0)$ and P22 $(x=4)$ have been previously studied. P17 shows good balance between capacities and HRD [26], and P22 was the subject of the annealing condition matrix study [25]. The new compositions extend the study of V-content versus Ni-content. ICP results from the ingot samples are listed in Table 1. Other than a small but consistent deficiency in $\mathrm{Zr}$ (due to formation of $\mathrm{ZrO}_{2}$ as oxygen scavenger), the ICP results are very close to the target compositions. The measured $\mathrm{B} / \mathrm{A}$ ratios are slightly higher than the designed values due to the loss in $\mathrm{Zr}$.

Table 1. Design compositions and inductively coupled plasma (ICP) results for alloys in this study. All numbers are in at\%.

\begin{tabular}{ccccccccccc}
\hline \multicolumn{2}{c}{ Alloy } & $\mathbf{T i}$ & $\mathbf{Z r}$ & $\mathbf{V}$ & $\mathbf{C r}$ & $\mathbf{M n}$ & $\mathbf{C o}$ & $\mathbf{N i}$ & $\mathbf{A l}$ & $\mathbf{B} / \mathbf{A}$ \\
\hline \multirow{2}{*}{ P17 } & Design & 15.6 & 2.1 & 44.0 & 11.2 & 6.9 & 1.4 & 18.5 & 0.3 & 4.65 \\
& ICP & 15.6 & 2 & 44.1 & 11.3 & 6.4 & 1.4 & 18.9 & 0.3 & 4.68 \\
\hline \multirow{2}{*}{ P22 } & Design & 15.6 & 2.1 & 40.0 & 11.2 & 6.9 & 1.4 & 22.5 & 0.3 & 4.65 \\
& ICP & 15.5 & 1.8 & 41.0 & 11.2 & 6.5 & 1.4 & 22.2 & 0.4 & 4.78 \\
\hline \multirow{2}{*}{ P23 } & Design & 15.6 & 2.1 & 38.0 & 11.2 & 6.9 & 1.4 & 24.5 & 0.3 & 4.65 \\
& ICP & 15.2 & 1.7 & 38.7 & 11.4 & 6.8 & 1.4 & 24.3 & 0.4 & 4.91 \\
\hline \multirow{2}{*}{ P24 } & Design & 15.6 & 2.1 & 36.0 & 11.2 & 6.9 & 1.4 & 26.5 & 0.3 & 4.65 \\
& ICP & 15.5 & 1.8 & 36.0 & 11.3 & 6.4 & 1.5 & 27.1 & 0.4 & 4.78 \\
\hline \multirow{2}{*}{ P25 } & Design & 15.6 & 2.1 & 34.0 & 11.2 & 6.9 & 1.4 & 28.5 & 0.3 & 4.65 \\
& ICP & 15.5 & 1.8 & 34.4 & 11.4 & 6.6 & 1.4 & 28.4 & 0.4 & 4.77 \\
\hline \multirow{2}{*}{ P26 } & Design & 15.6 & 2.1 & 32.0 & 11.2 & 6.9 & 1.4 & 30.5 & 0.3 & 4.65 \\
& ICP & 15.5 & 1.7 & 33.5 & 10.8 & 6.8 & 1.5 & 29.8 & 0.4 & 4.81 \\
\hline \multirow{2}{*}{ P27 } & Design & 15.6 & 2.1 & 30.0 & 11.2 & 6.9 & 1.4 & 32.5 & 0.3 & 4.65 \\
& ICP & 15.2 & 1.8 & 30.6 & 11.7 & 6.6 & 1.4 & 32.2 & 0.4 & 4.88 \\
\hline \multirow{2}{*}{ P28 } & Design & 15.6 & 2.1 & 28.0 & 11.2 & 6.9 & 1.4 & 34.5 & 0.3 & 4.65 \\
& ICP & 15.3 & 1.9 & 28.1 & 11.4 & 6.6 & 1.4 & 34.9 & 0.4 & 4.81 \\
\hline
\end{tabular}




\subsection{X-Ray Diffractometer Structure Analysis}

XRD patterns of the eight alloys are shown in Figure 1. Five sets of diffraction peaks are observed: a BCC, two Laves phases (C14 and C15), a TiNi and a $\sigma-\mathrm{VNi}$. As the Ni-content in the alloy increases, the BCC peaks shift to higher angles, $\mathrm{C} 14$ phase is replaced by $\mathrm{C} 15$ phase, and $\sigma$-VNi phase starts to appear. $\sigma$-VNi phase is in a tetragonal structure, and the lattice constants are $a=8.966 \AA$ and $c=4.641 \AA$ with a composition at $\mathrm{V}_{0.6} \mathrm{Ni} 0.4$ [33]. It has wide solubility in $\mathrm{V}$ from 57.5 at $\%$ to 75 at $\%$ [34]. The $\mathrm{V}-\mathrm{Ni}-\mathrm{Cr}$ ternary phase diagram indicates an extension of $\sigma$-VNi phase from $0 \%$ to about $40 \% \mathrm{Cr}$ [35].

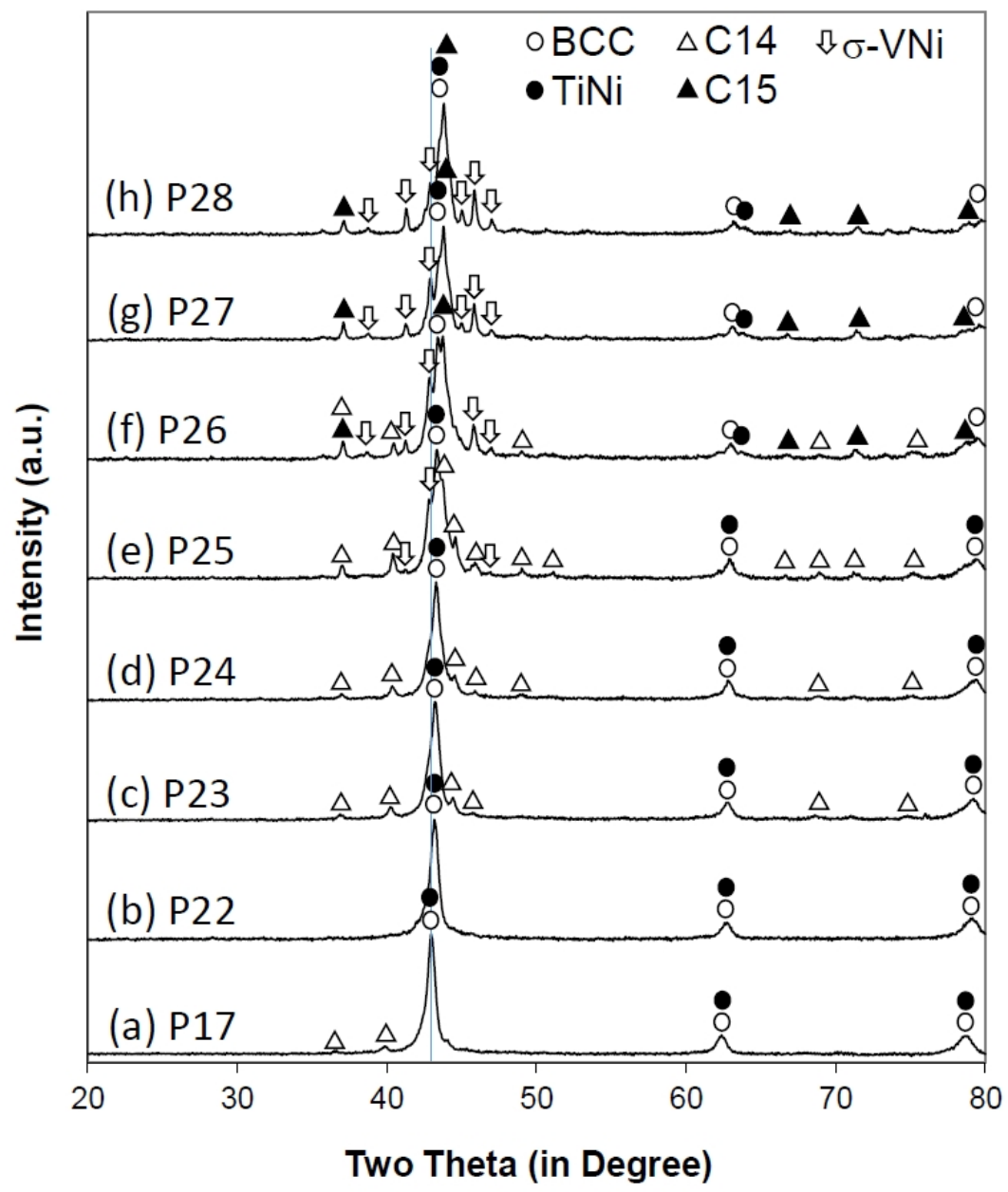

Figure 1. X-ray diffractometer (XRD) patterns using $\mathrm{Cu}-\mathrm{K} \alpha$ as the radiation source for alloys: (a) P17; (b) P22; (c) P23; (d) P24; (e) P25; (f) P26; (g) P27; and (h) P28. A vertical line is used to indicate the shift in body-centered-cubic (BCC) peaks.

Lattice constants, crystallite sizes, and phase abundances of all five constituent phases calculated from the XRD patterns are listed in Table 2. The variations in lattice constants from BCC, C14, and TiNi phases are plotted in Figure 2. As the amount of Ni increases, the lattice constant $a$ in BCC first remains constant and then decreases, both $a$ and $c$ in $\mathrm{C} 14$ phase decrease at about the same rate yielding a slight decrease in $c / a$ ratio, while $a$ in TiNi sees a discontinuous two-segment decrease. The changes in lattice constants for $\mathrm{C} 15$ and $\mathrm{VNi}$ are less prominent. Lattice parameter $a$ in BCC phase decreases from $2.977 \AA$ to $2.946 \AA$ as the Ni-content in the alloy increases, which is further away from the optimized value of $3.042 \AA$ corresponding to a maximized hydrogen storage capacity [36]. 
Table 2. Lattice parameters, unit cell volumes, phase abundances, and crystallite sizes of phases derived from XRD analysis. $X S$ denotes crystallite size.

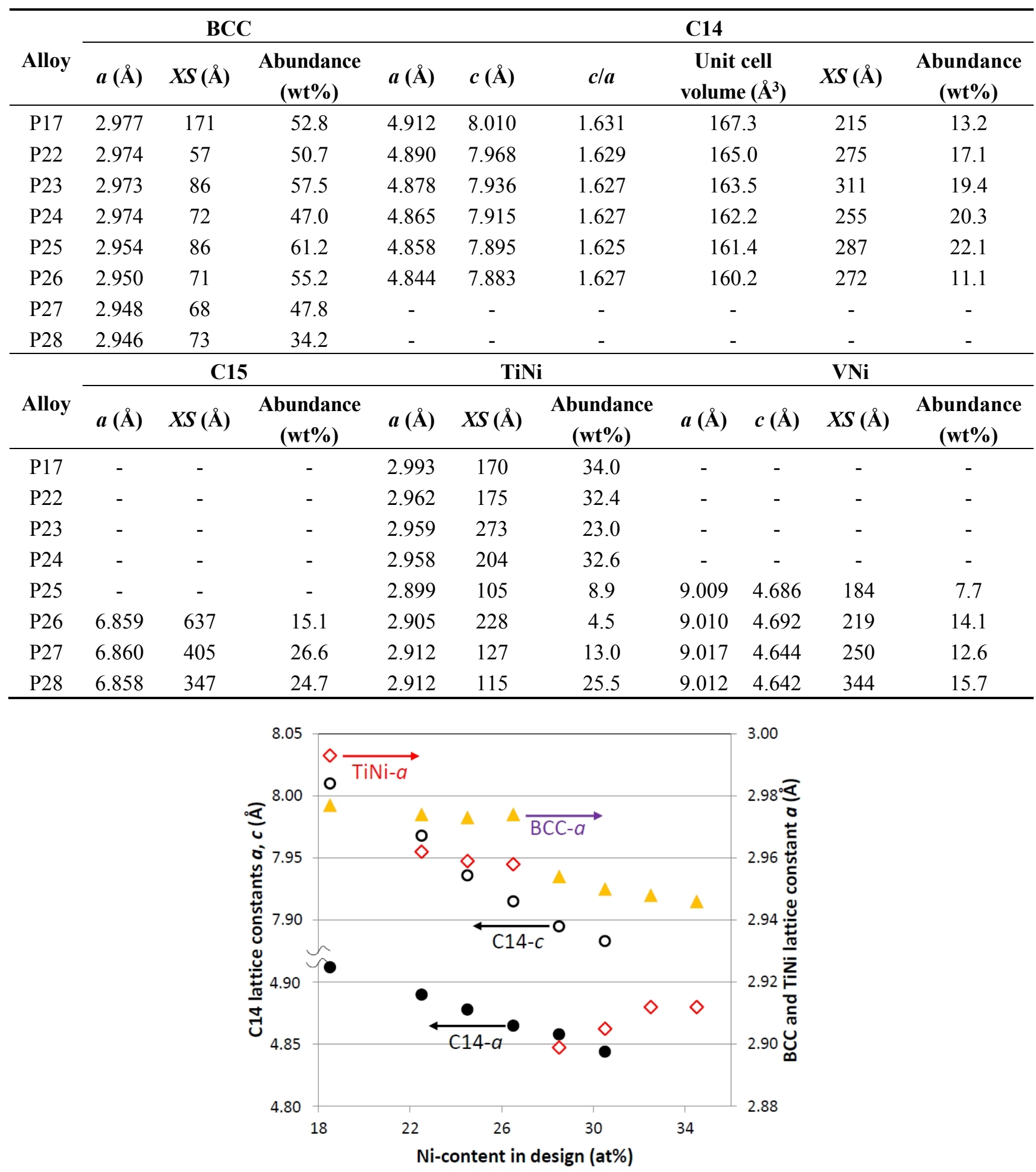

Figure 2. Lattice constants $a$ and $c$ from $\mathrm{C} 14$ phase, and lattice constants $a$ from BCC and TiNi phases as functions of Ni-content in design.

Phase abundance and crystallite sizes of each phase are listed in Table 2 . These values were obtained from full pattern fitting of the XRD data using the Rietveld method and Jade 9 Software (KS Analytical System, Aubrey, TX, USA). 
The evolution of phase abundance is plotted in Figure 3. C14 Laves phase abundance first increases and then decreases as it is replaced by another Laves phase- $\mathrm{C} 15$ phase. The total Laves phase abundance generally increases, but begins to taper and decrease as it is changed to C15 phase. TiNi phase abundance varies widely as it first decreases, then increases, decreases, and finally increases again. BCC phase constitutes about 50-60 wt $\%$ and then drops to below $40 \mathrm{wt} \%$. $\sigma$-VNi-phase appears in alloys with higher Ni-content, and the abundance further increases. The crystallite sizes $(X S)$ of all five constituent phases have different trends. As the Ni-content in the alloy increases at the expense of $\mathrm{V}$, the $X S$ of BCC and $\mathrm{C} 15$ phases decrease, the $X S$ of $\mathrm{C} 14$ and TiNi phases first increase and then decrease, and in VNi phase, the $X S$ increases.

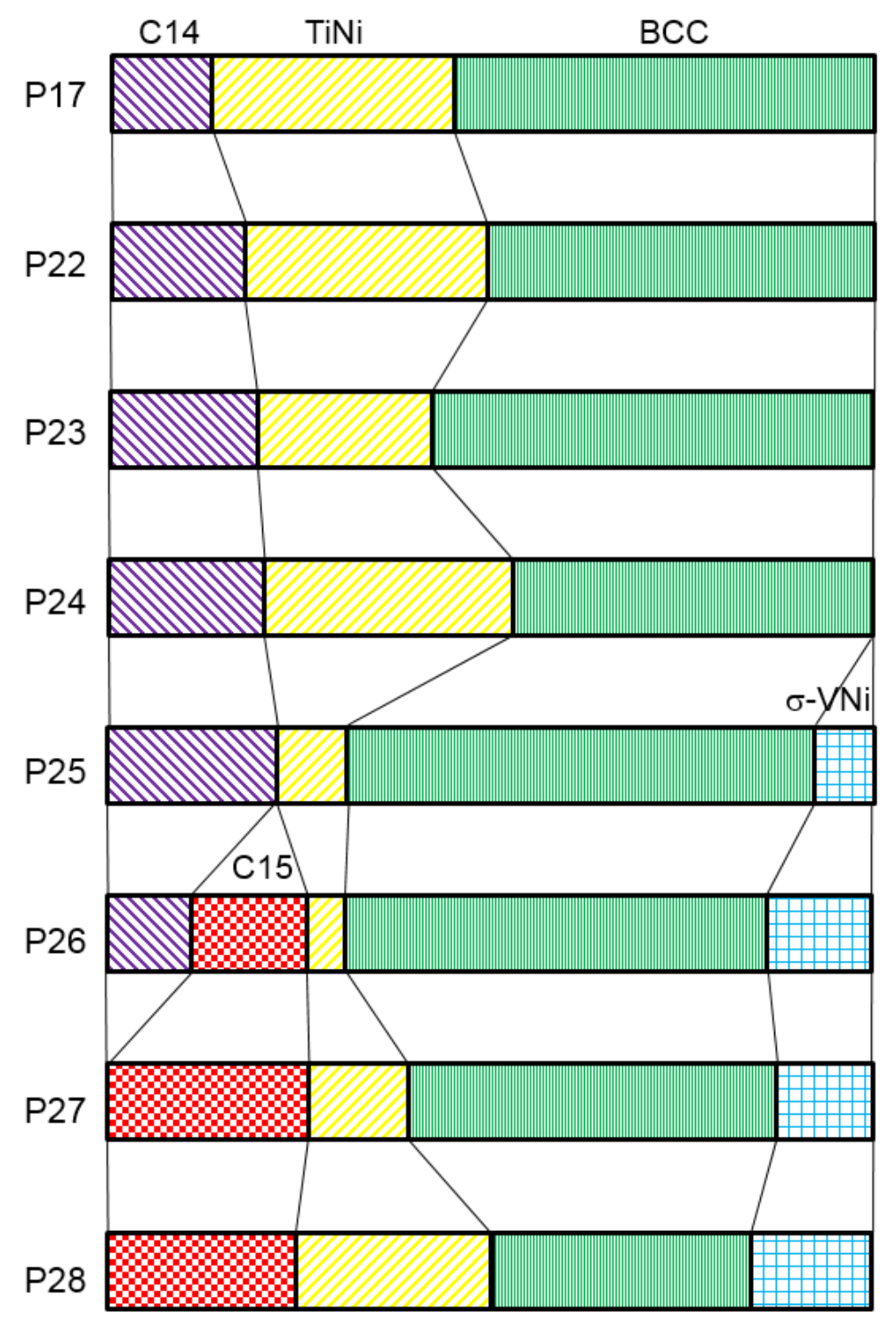

Figure 3. Evolution in the phase abundances of constituent phases from the full-pattern analysis of XRD data.

\subsection{Scanning Electron Microscope/Energy Dispersive Spectroscopy Microstructure Analysis}

Microstructures for this series of alloys were studied using SEM, and the resulting back-scattering electron images (BEI) are presented in Figure 4. 

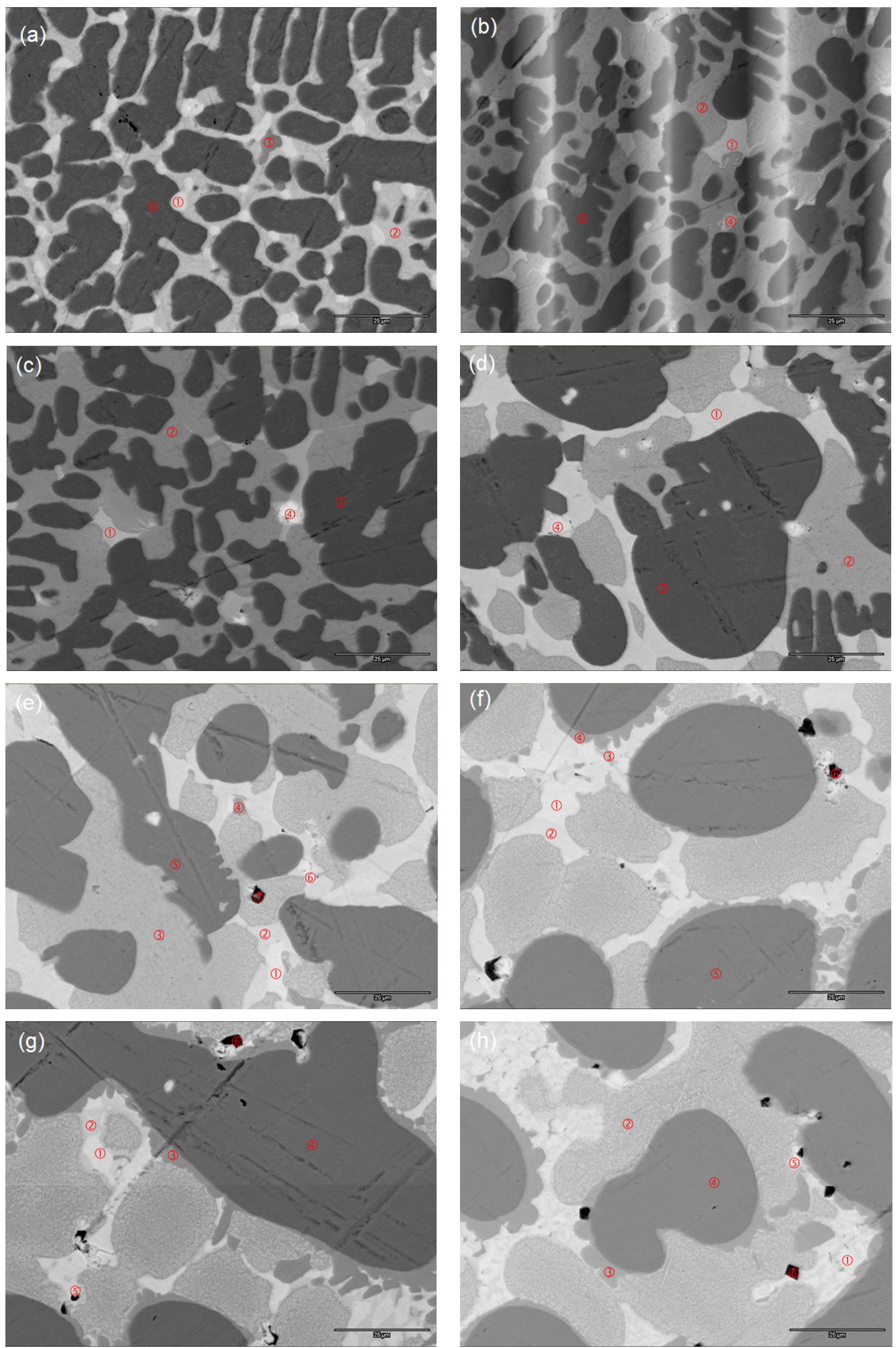

Figure 4. Scanning electron microscope (SEM) back-scattering electron images (BEI) for alloys: (a) P17; (b) P22; (c) P23; (d) P24; (e) P25; (f) P26; (g) P27; and (h) P28. Chemical compositions in the numbered areas measured by EDS are listed in Table 3. 
Table 3. Energy dispersive spectroscopy (EDS) composition data from select spots in Figure 3. All numbers are in at\%. B/A ratios for $\mathrm{C} 14$ and $\mathrm{C} 15$ phases were calculated assuming $\mathrm{V}$ is in the B-site while those in TiNi and VNi phases were calculated assuming $\mathrm{V}$ in the A-site. Compositions in the main BCC phase are highlighted in bold.

\begin{tabular}{|c|c|c|c|c|c|c|c|c|c|c|c|c|}
\hline Location & $\mathbf{Z r}$ & Ti & $\mathbf{V}$ & $\mathrm{Cr}$ & Mn & $\mathbf{F e}$ & Co & $\mathbf{N i}$ & Al & $\mathbf{B} / \mathbf{A}$ & $e / a$ & Phase \\
\hline Figure 4a-1 & 16.2 & 16.3 & 7.8 & 4.4 & 5.9 & 0.0 & 1.8 & 47.5 & 0.1 & 2.08 & 7.28 & $\mathrm{C} 14$ \\
\hline Figure $4 a-2$ & 4.7 & 36.4 & 7.8 & 0.8 & 3.6 & 0.0 & 2.0 & 44.4 & 0.3 & 1.04 & - & TiNi \\
\hline Figure $4 a-3$ & 6.2 & 48.5 & 11.7 & 1.2 & 2.3 & 0.0 & 1.8 & 28.3 & 0.1 & 0.51 & - & $\mathrm{Ti}_{2} \mathrm{Ni}$ \\
\hline Figure 4a-4 & 0.1 & 5.5 & 63.5 & 16.9 & 7.4 & 0.0 & 0.8 & 5.6 & 0.2 & - & - & BCC \\
\hline Figure $4 b-1$ & 14.3 & 17.3 & 9.4 & 0.6 & 4.8 & 0.0 & 0.8 & 52.5 & 0.3 & 2.16 & 7.44 & $\mathrm{C} 14$ \\
\hline Figure $4 b-2$ & 2.8 & 34.3 & 7.3 & 0.9 & 4.7 & 0.1 & 2.7 & 46.4 & 0.8 & 1.25 & - & TiNi \\
\hline Figure $4 b-3$ & 0.1 & 3.0 & 60.7 & 17.7 & 11.8 & 0.0 & 0.9 & 5.7 & 0.1 & - & - & BCC \\
\hline Figure $4 b-4$ & 87.2 & 3.0 & 3.1 & 0.5 & 0.8 & 0.1 & 0.4 & 4.8 & 0.1 & - & - & $\mathrm{Zr}$ \\
\hline Figure $4 c-1$ & 12.0 & 18.6 & 12.4 & 0.7 & 3.5 & 0.0 & 0.9 & 51.6 & 0.3 & 2.27 & 7.38 & $\mathrm{C} 14$ \\
\hline Figure $4 c-2$ & 2.4 & 34.5 & 8.4 & 1.0 & 3.7 & 0.0 & 2.3 & 47.2 & 0.5 & 1.21 & - & TiNi \\
\hline Figure $4 c-3$ & 0.1 & 4.5 & 58.1 & 18.2 & 8.6 & 0.0 & 1.1 & 9.3 & 0.1 & - & - & BCC \\
\hline Figure $4 c-4$ & 93.9 & 1.1 & 2.5 & 0.4 & 0.3 & 0.1 & 0.1 & 1.5 & 0.1 & - & - & $\mathrm{Zr}$ \\
\hline Figure 4d-1 & 10.6 & 17.9 & 16.5 & 2.5 & 4.7 & 0.0 & 1.4 & 46.2 & 0.2 & 2.51 & 7.20 & $\mathrm{C} 14$ \\
\hline Figure $4 d-2$ & 1.9 & 33.9 & 8.6 & 1.1 & 3.5 & 0.0 & 2.4 & 47.6 & 1.0 & 1.25 & - & TiNi \\
\hline Figure 4d-3 & 0.0 & 2.3 & 60.0 & 21.1 & 8.3 & 0.0 & 1.0 & 7.1 & 0.2 & - & - & BCC \\
\hline Figure $4 d-4$ & 94.7 & 0.7 & 1.8 & 0.4 & 0.1 & 0.0 & 0.2 & 1.9 & 0.2 & - & - & $\mathrm{Zr}$ \\
\hline Figure $4 \mathrm{e}-1$ & 10.8 & 16.0 & 14.2 & 1.8 & 4.2 & 0.0 & 1.0 & 51.7 & 0.3 & 2.73 & 7.45 & $\mathrm{C} 15$ \\
\hline Figure $4 \mathrm{e}-2$ & 8.5 & 17.7 & 18.2 & 2.5 & 5.0 & 0.0 & 1.5 & 46.2 & 0.3 & 2.81 & 7.22 & $\mathrm{C} 14$ \\
\hline Figure $4 \mathrm{e}-3$ & 1.6 & 33.8 & 8.6 & 1.1 & 4.1 & 0.1 & 2.5 & 47.5 & 0.8 & 1.28 & - & TiNi \\
\hline Figure $4 \mathrm{e}-4$ & 0.2 & 7.0 & 48.2 & 6.6 & 5. & 0.1 & 1.3 & 31.3 & 0.1 & 0.81 & - & $\mathrm{VNi}$ \\
\hline Figure 4e-5 & 0.0 & 2.4 & 58.7 & 21.8 & 8.5 & 0.0 & 1.0 & 7.4 & 0.1 & - & - & BCC \\
\hline Figure $4 \mathrm{e}-6$ & 89.0 & 3.2 & 2.4 & 0.4 & 0.2 & 0.0 & 0.2 & 4.5 & 0.1 & - & - & $\mathrm{Zr}$ \\
\hline Figure $4 \mathrm{e}-7$ & 4.7 & 69.5 & 7.8 & 1.3 & 1.6 & 0.0 & 0.6 & 14.1 & 0.3 & - & - & $\mathrm{TiO}_{2}$ \\
\hline Figure $4 \mathrm{f}-1$ & 10.5 & 16.2 & 13.3 & 1.9 & 4.4 & 0.0 & 1.0 & 52.5 & 0.2 & 2.75 & 7.50 & $\mathrm{C} 15$ \\
\hline Figure $4 \mathrm{f}-2$ & 8.9 & 17.3 & 15.7 & 2.5 & 5.1 & 0.0 & 1.4 & 48 & 0.2 & 2.81 & 7.35 & $\mathrm{C} 14$ \\
\hline Figure $4 \mathrm{f}-3$ & 1.4 & 30.7 & 10.3 & 1.1 & 5.1 & 0.0 & 2.0 & 48.6 & 0.8 & 1.36 & - & TiNi \\
\hline Figure $4 \mathrm{f}-4$ & 0.2 & 6.8 & 48.4 & 7.1 & 6.8 & 0.0 & 1.5 & 29.0 & 0.1 & 0.80 & - & $\mathrm{VNi}$ \\
\hline Figure 4f-5 & 0.0 & 2.1 & 58.3 & 21.6 & 8.7 & 0.0 & 1.1 & 8.0 & 0.1 & - & - & BCC \\
\hline Figure $4 \mathrm{f}-6$ & 6.0 & 79.0 & 8.3 & 0.1 & 0.5 & 0.0 & 0.2 & 6.0 & 0.0 & - & - & $\mathrm{TiO}_{2}$ \\
\hline Figure 4g-1 & 10.4 & 16.5 & 11.9 & 2.1 & 5.2 & 0.1 & 1.2 & 52.4 & 0.3 & 2.72 & 7.53 & $\mathrm{C} 15$ \\
\hline Figure $4 \mathrm{~g}-2$ & 4.5 & 30.2 & 9.2 & 1.0 & 5.0 & 0.0 & 1.0 & 48.8 & 0.2 & 1.28 & - & TiNi \\
\hline Figure $4 g-3$ & 0.1 & 6.6 & 46.2 & 9.4 & 6.6 & 0.0 & 1.8 & 29.3 & 0.1 & 0.89 & - & $\mathrm{VNi}$ \\
\hline Figure 4g-4 & 0.0 & 1.8 & 55.4 & 25.3 & 8.6 & 0.0 & 1.1 & 7.6 & 0.1 & - & - & BCC \\
\hline Figure $4 g-5$ & 85.5 & 5.1 & 2.1 & 0.5 & 0.6 & 0.2 & 0.1 & 5.8 & 0.1 & - & - & $\mathrm{Zr}$ \\
\hline Figure $4 g-6$ & 3.5 & 82.8 & 7.6 & 0.1 & 0.6 & 0.0 & 0.1 & 5.2 & 0.1 & - & - & $\mathrm{TiO}_{2}$ \\
\hline Figure $4 \mathrm{~h}-1$ & 10.2 & 16.2 & 11.8 & 2.4 & 5.5 & 0.0 & 1.1 & 52.5 & 0.3 & 2.79 & 7.53 & $\mathrm{C} 15$ \\
\hline Figure $4 \mathrm{~h}-2$ & 1.3 & 30.1 & 9.1 & 1.0 & 6.3 & 0.0 & 2.3 & 49.0 & 0.9 & 1.47 & - & TiNi \\
\hline Figure $4 \mathrm{~h}-3$ & 0.1 & 6.6 & 43.5 & 11.6 & 6.8 & 0.2 & 1.8 & 29.2 & 0.2 & 0.99 & - & $\mathrm{VNi}$ \\
\hline Figure $4 \mathrm{~h}-4$ & 0.0 & 1.7 & 53.0 & 27.4 & 8.3 & 0.0 & 1.2 & 8.3 & 0.1 & - & - & BCC \\
\hline Figure $4 \mathrm{~h}-5$ & 86.1 & 3.9 & 2.2 & 0.4 & 0.7 & 0.0 & 0.2 & 6.2 & 0.2 & - & - & $\mathrm{Zr}$ \\
\hline Figure $4 \mathrm{~h}-6$ & 2.0 & 90.6 & 3.3 & 0.1 & 0.5 & 0.0 & 0.2 & 3.3 & 0.1 & - & - & $\mathrm{TiO}_{2}$ \\
\hline
\end{tabular}


EDS analysis was used to study the chemical compositions of several areas showing different contrasts and the results are summarized in Table 3. In the case of BCC-C14 dual-phase alloy, during cooling of the melt, BCC phase with high V-content solidifies first to form a three-dimensional framework while the rest of the liquid solidifies into Laves phase as the alloy cools further. The Laves phase itself is also a three-dimensional framework (Figure 4 in [37]). This interlacing dual-framework can be seen in the alloys in the current study, but the framework has less alignment. The main BCC phase is shown in a darker contrast due to its low $\mathrm{Zr}$ - and Ni-contents (lower average atomic weight). The grain size of the main BCC phase increases but the crystallite size decreases (as seen from the XRD analysis) as the Ni-content in the alloy increases. The majority of the secondary phases is in the BCC phase grain boundary, and it evolves from $\mathrm{TiNi}+\mathrm{C} 14+\mathrm{Ti}_{2} \mathrm{Ni}(\mathrm{P} 17$, very small amount and not detectable by XRD) to $\mathrm{TiNi}+\mathrm{C} 14+\mathrm{Zr}(\mathrm{P} 22-\mathrm{P} 24), \mathrm{TiNi}+\mathrm{C} 14+\mathrm{C} 15+\mathrm{VNi}+\mathrm{Zr}+\mathrm{TiO}_{2}(\mathrm{P} 25, \mathrm{P} 26)$, and $\mathrm{TiNi}+\mathrm{C} 15+\mathrm{VNi}+\mathrm{Zr}+\mathrm{TiO}_{2}(\mathrm{P} 27, \mathrm{P} 28)$. The average electron density $(e / a)$ calculated from the measured composition was used to distinguish the $\mathrm{C} 14$ and $\mathrm{C} 15$ Laves phases. The e/a values are listed in Table 3, and in this case, the $\mathrm{C} 14 / \mathrm{C} 15$ threshold falls at a value of $7.45[38,39]$. The VNi phase starts at the center of the secondary phase region (Figure 4e-4) and moves to the boundary between BCC main phase and other secondary phases (TiNi and Laves). It is clear from the V-Ni phase diagram that the cooling sequence is first BCC phase, followed by $\sigma-\mathrm{VNi}$ phase and finally ending with a $\mathrm{VNi}_{2}$ (oI6 structure) $+\sigma$-VNi mixture [34]. In our multi-element case, the final $\mathrm{VNi}_{2}$ is replaced by a combination of TiNi and Laves phases.

The atomic percentages of a few key elements in BCC, TiNi, and C14 phases examined by SEM/EDS are plotted in Figure 5 as functions of $\mathrm{Ni}$-content in the overall alloy design. Since the sampling volume of one spot in the EDS analysis is very limited (up to a few microns in diameter), the results may not be very representative and should be interpreted with caution. In the main BCC phase, as the Ni-content increases at the expense of $\mathrm{V}$, the $\mathrm{V}$-content decreases, the $\mathrm{Cr}$-content increases, and the $\mathrm{Mn}$ - and $\mathrm{Ni}$-contents remain at about the same values (Figure 5a). Because $\mathrm{Cr}$ is smaller than $\mathrm{V}$, this decreases the lattice constant in BCC phase. $\mathrm{V}$ is a hydride former, and a smaller unit cell with less $\mathrm{V}$-content has direct impacts on several properties: the metal-hydrogen bond strength will be weaker (better HRD), the plateau pressure will be higher, and the storage capacity will be lower. In the TiNi phase, as the $\mathrm{Ni}$-content in design increases, the Ni-content increases, the Ti-content decreases, and the $\mathrm{V}$ - and $\mathrm{Mn}$-contents remain relatively unchanged (Figure 5b). Because $\mathrm{Ni}$ is smaller than $\mathrm{Ti}$, this results in a smaller unit cell, which is also beneficial in the TiNi catalytic phase for easier hydrogen diffusion. In the $\mathrm{C} 14$ phase, as the Ni-content in design increases, the $\mathrm{Zr}$-content decreases, the $\mathrm{V}$-content increases, and $\mathrm{Ti}$ and Ni remain unchanged. The decrease in $\mathrm{Zr}$ is due to the fact that Laves phase contains most of the $\mathrm{Zr}$ and its abundance in Laves phase increases with the increase in $\mathrm{Ni}$. The overall $\mathrm{Zr}$-content is fixed; therefore, the $\mathrm{Zr}$-content in Laves phase is diluted and the heavily over-stoichiometry $(\mathrm{B} / \mathrm{A}>2.0)$ invites more $\mathrm{V}$ into the Laves phase. Both the lattice constants $a$ and $c$ decrease as more $\mathrm{Zr}$ (larger) is replaced by $\mathrm{V}$ (smaller). The relatively constant $c / a$ indicates that most of the $\mathrm{V}$ sits in the A-site since a relatively large substitution in the B-site will cause an anisotropic enlargement in the unit cell [40,41]. The shrinkage in catalytic $\mathrm{C} 14$ phase unit cell also facilitates hydrogen diffusion in the alloy bulk. 


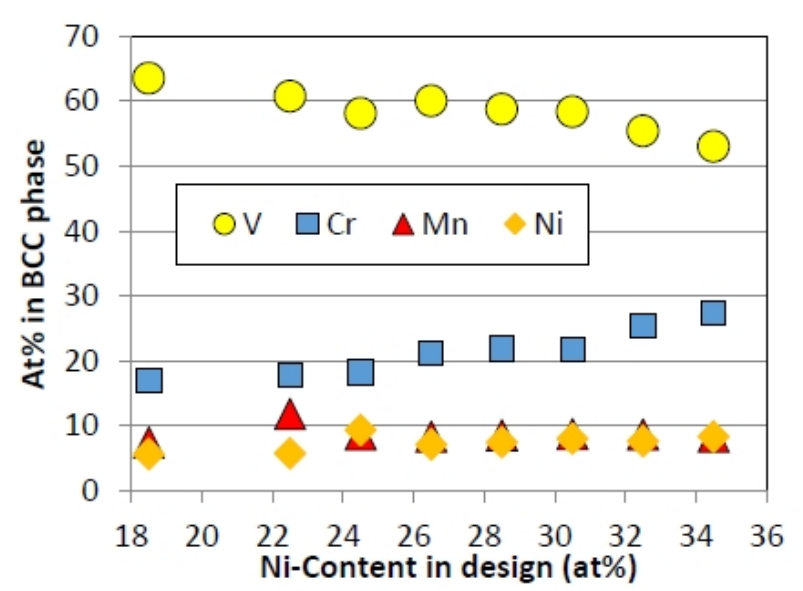

(a)

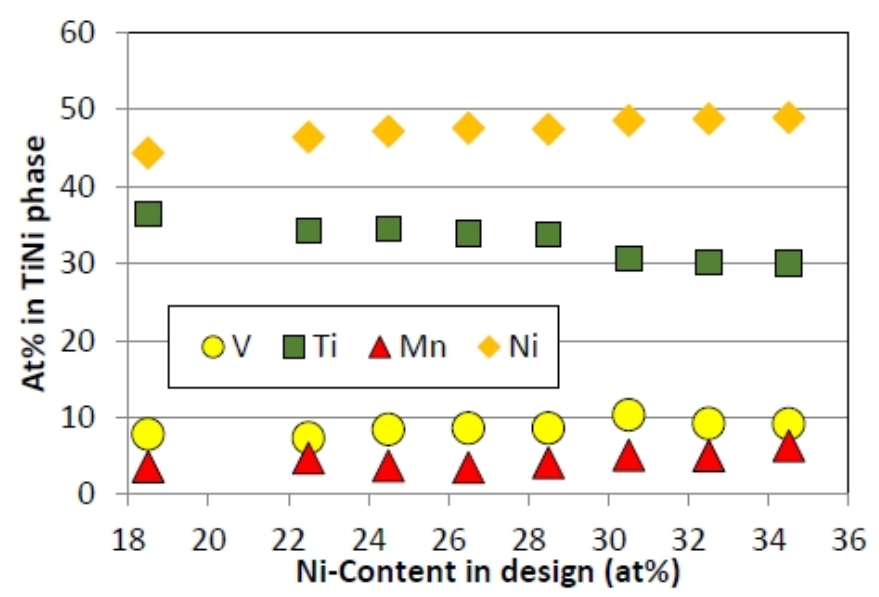

(b)

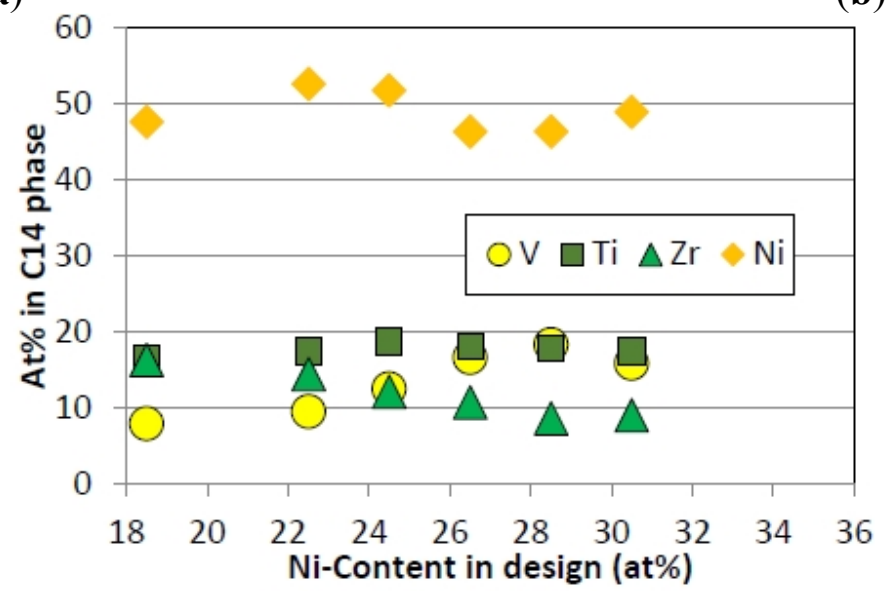

(c)

Figure 5. Atomic percentages of key elements in: (a) BCC; (b) TiNi; and (c) C14 phases as functions of Ni-content in design.

\subsection{Gaseous Phase Study}

Gaseous phase hydrogen storage properties of the alloys were studied by PCT. All samples are activated with one thermal cycle in the presence of hydrogen. Consequent measurements did not change the PCT characteristic significantly. The resulting absorption and desorption isotherms measured at $30^{\circ} \mathrm{C}$ and $60{ }^{\circ} \mathrm{C}$ are shown in Figure 6. Information obtained from the PCT study is summarized in Table 4. A two-phase characteristic can be observed in alloys P22-P24. The heat of hydride formation of each of the phases can be estimated from the atomic percentages and the heats of hydride formation $\left(\Delta H_{\mathrm{h}}\right)$ for the three main hydride-former atoms, i.e., $\mathrm{Zr}\left(\Delta H_{\mathrm{h}}=-163 \mathrm{~kJ} \cdot \mathrm{mol} \mathrm{H}_{2}{ }^{-1}\right.$ for $\left.\mathrm{ZrH}_{2}\right)$, Ti $\left(\Delta H_{\mathrm{h}}=-124 \mathrm{~kJ} \cdot \mathrm{mol} \mathrm{H}_{2}^{-1}\right.$ for $\left.\mathrm{TiH}_{2}\right)$, and $\mathrm{V}\left(\Delta H_{\mathrm{h}}=-34 \mathrm{~kJ} \cdot \mathrm{mol} \mathrm{H}_{2}^{-1}\right.$ for $\left.\mathrm{VH}_{2}\right)$ [42]. For example, the calculated $\Delta H_{\mathrm{h}}$ for TiNi will be $-62 \mathrm{~kJ} \cdot \mathrm{mol} \mathrm{H}_{2}{ }^{-1}$, which is close to the experimental result of $-60 \mathrm{~kJ} \cdot \mathrm{mol} \mathrm{H}_{2}{ }^{-1}$ [43]. The such-obtained $\Delta H_{\mathrm{h}}$ for the constituent phases for P22 are $-25.5(\mathrm{BCC})$, -49.6 (TiNi), and $-46.8 \mathrm{~kJ} \cdot \mathrm{mol} \mathrm{H}_{2}{ }^{-1}$ (C14). Therefore, the main plateau at higher equilibrium pressure in the PCT isotherm for P22 alloy is attributed to the main BCC phase, and the second plateau, which occurs at lower hydrogen concentration and lower equilibrium pressure, is attributed to the combination of TiNi and $\mathrm{C} 14$ secondary phases. The same estimation is performed on alloy P26, and the results are -22.4 (BCC), -25.2 (VNi), -43.8 ( TiNi), -41.3 (C14), and $-41.7 \mathrm{~kJ} \cdot \mathrm{mol} \mathrm{H}_{2}^{-1}$ (C15). The first two phases 
(BCC and $\mathrm{VNi}$ ) are considered to be storage phases, which are responsible for the plateau in the PCT isotherm, and the other three phases with higher Ni-content are the catalytic phases that do not contribute directly to the hydrogen storage capacity.

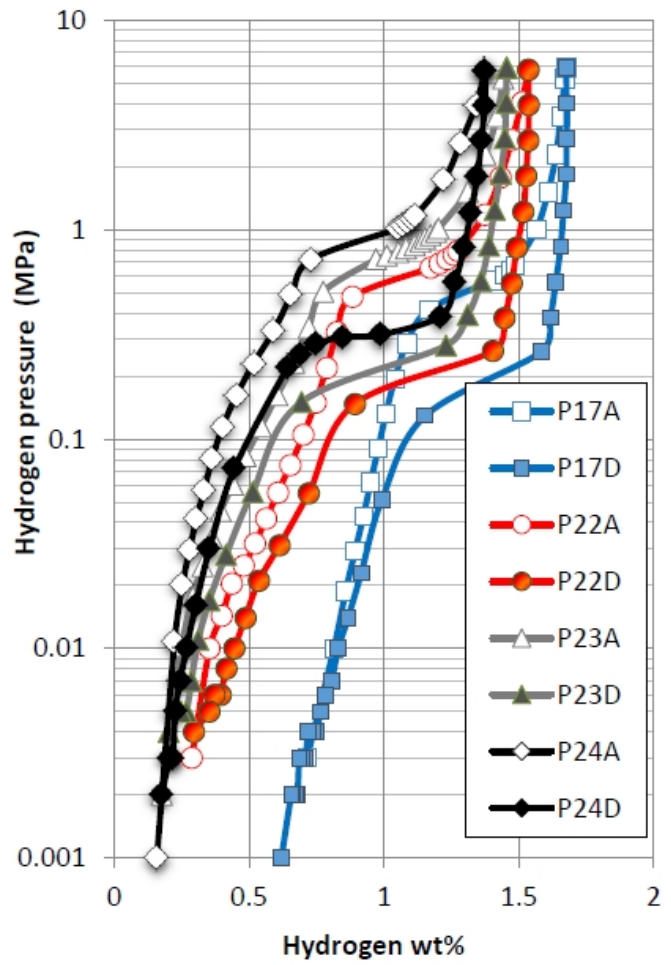

(a)

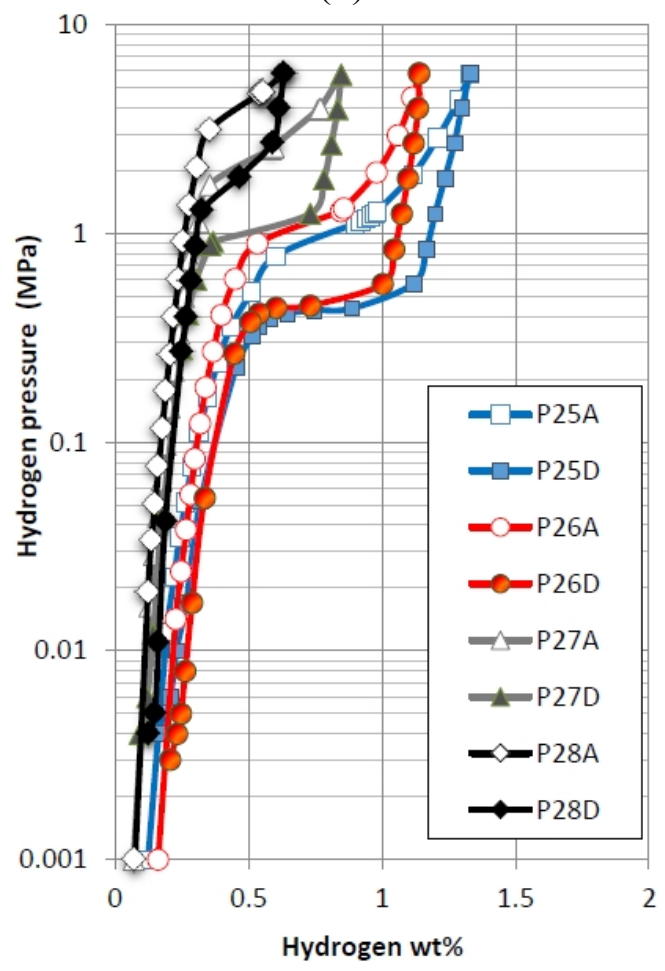

(c)

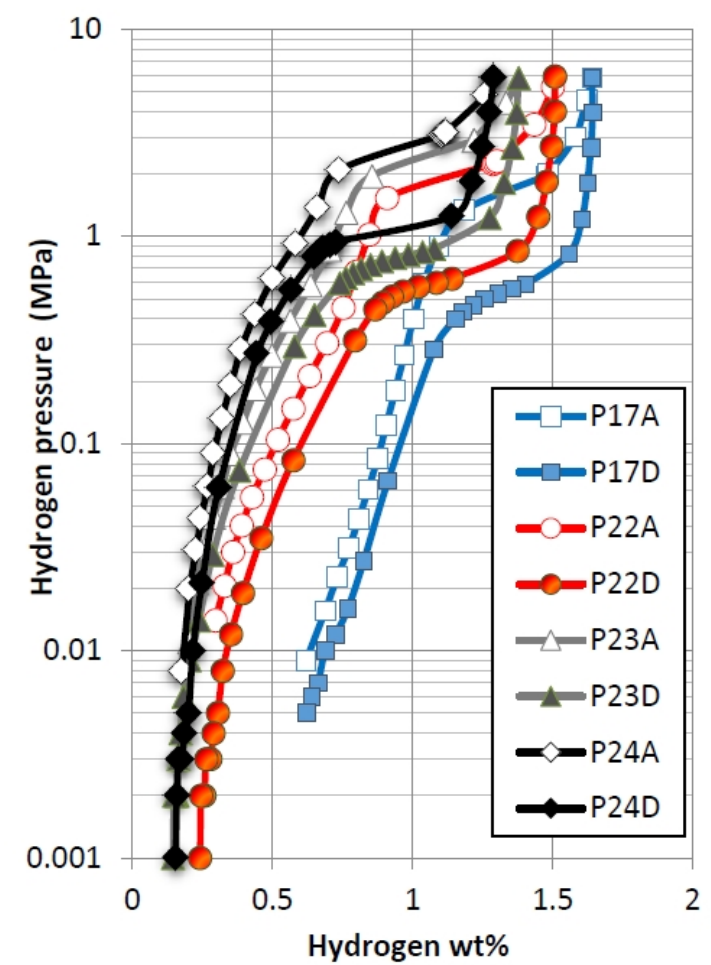

(b)

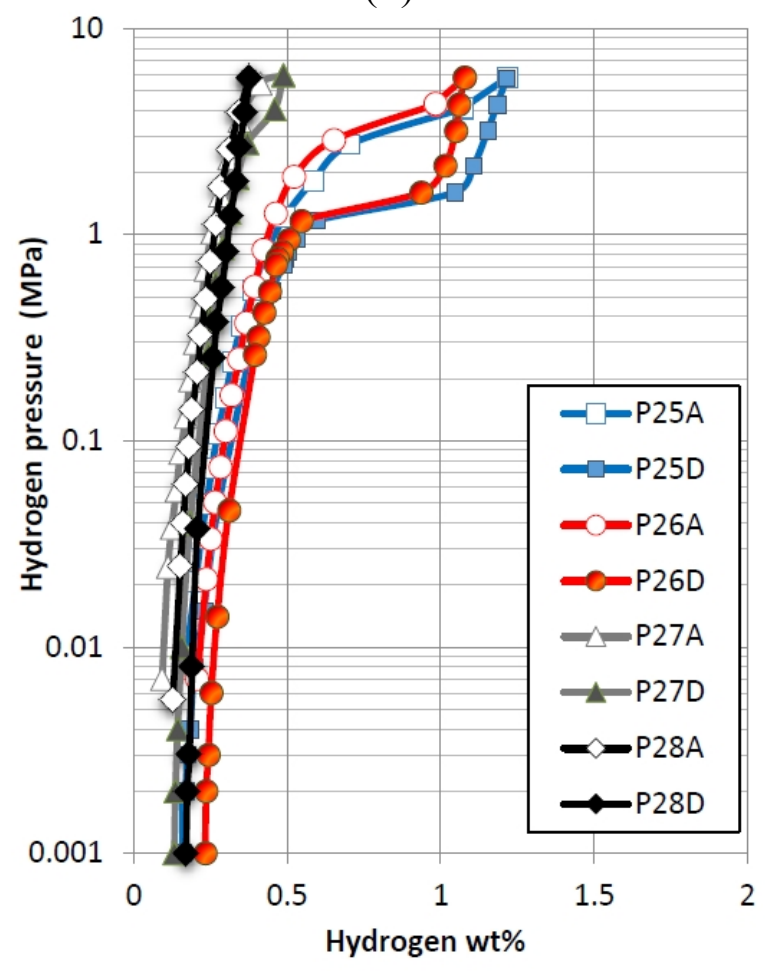

(d)

Figure 6. (a) $30{ }^{\circ} \mathrm{C}$ and (b) $60^{\circ} \mathrm{C}$ pressure-concentration-temperature (PCT) isotherms of alloys P17, P22, P23, P24; and (c) $30^{\circ} \mathrm{C}$ and (d) $60{ }^{\circ} \mathrm{C}$ of alloys P25, P26, P27, and P28. Open and solid symbols are for absorption and desorption curves, respectively. 
Table 4. Summary of gaseous phase and thermodynamic properties. The $\Delta H$ and $\Delta S$ were calculated from the equilibrium pressure plateaus measured at 30,60 , and $90{ }^{\circ} \mathrm{C}$ with the error bars of about $\pm 2 \%$.

\begin{tabular}{|c|c|c|c|c|c|c|c|c|}
\hline $\begin{array}{c}\text { Alloy } \\
\text { No. }\end{array}$ & $\begin{array}{c}\text { Desorption } \\
\text { pressure } \\
\text { @ } 30^{\circ} \mathrm{C}\end{array}$ & $\begin{array}{c}\text { Desorption } \\
\text { pressure } \\
\text { @ } 60^{\circ} \mathrm{C}\end{array}$ & $\begin{array}{c}\text { Maximum } \\
\text { capacity } \\
\text { @ } 30^{\circ} \mathrm{C}\end{array}$ & $\begin{array}{c}\text { Reversible } \\
\text { capacity } \\
\text { @ } 30^{\circ} \mathrm{C}\end{array}$ & $\begin{array}{c}\text { PCT } \\
\text { hysteresis }\end{array}$ & $\begin{array}{c}\text { PCT } \\
\text { hysteresis }\end{array}$ & $-\Delta \boldsymbol{H}$ & $-\Delta S$ \\
\hline & (MPa) & (MPa) & $(w t \%)$ & $(w t \%)$ & & & $\left(\mathrm{kJ} \cdot \mathrm{mol}^{-1}\right)$ & $\left(\mathrm{J} \cdot \mathrm{mol}^{-1} \cdot \mathbf{K}^{-1}\right)$ \\
\hline P17 & 0.17 & 0.53 & 1.68 & 1.01 & 1.06 & 1.10 & 30.9 & 107 \\
\hline P22 & 0.21 & 0.60 & 1.53 & 1.24 & 1.14 & 1.13 & 29.9 & 105 \\
\hline P23 & 0.22 & 0.79 & 1.45 & 1.25 & 1.20 & 1.06 & 35.3 & 123 \\
\hline P24 & 0.32 & 1.07 & 1.38 & 1.20 & 1.10 & 0.86 & 34.2 & 122 \\
\hline P25 & 0.45 & 1.42 & 1.33 & 1.16 & 0.77 & 0.82 & 32.1 & 119 \\
\hline P26 & 0.43 & 1.36 & 1.14 & 0.93 & 0.79 & 0.84 & 32.4 & 119 \\
\hline P27 & 1.06 & 3.20 & 0.85 & 0.75 & 0.79 & 0.46 & 31.0 & 122 \\
\hline P28 & 1.90 & - & 0.63 & 0.51 & 0.76 & - & - & - \\
\hline
\end{tabular}

As the Ni-content in the alloy increases, the plateau pressure in the $\mathrm{BCC}$ phase increases monotonically (due to the decrease in the $\mathrm{BCC}$ unit cell volume), the maximum storage capacity decreases, and the reversible storage first increases (due to the increase in abundance of catalytic C14 phase and the shrinkage in unit cell volumes for $\mathrm{BCC}$, TiNi, and $\mathrm{C} 14$ phases) and then decreases (due to the reduction in the maximum capacity). Hysteresis of the PCT isotherm is defined as $\ln \left(P_{\mathrm{a}} / P_{\mathrm{d}}\right)$, where $P_{\mathrm{a}}$ and $P_{\mathrm{d}}$ are the absorption and desorption equilibrium pressures at the main plateau (BCC phase), respectively. In general, the hysteresis measured at $30{ }^{\circ} \mathrm{C}$ divides the alloys into two groups: alloys with relatively low Ni-content (P17, P22-P24) that show higher hysteresis than those in the other group (P25-P28). PCT hysteresis represents the energy required to elastically distort the lattice at the metal/hydride interface [44]. The first alloys (P17, P22-P24) also have distinctively larger unit cells (Figure 2) and also are free of $\mathrm{C} 15$ and $\sigma-\mathrm{VNi}$ phases. The connection between PCT hysteresis and structural properties of these alloys requires further investigation.

In order to study the thermodynamic properties of these alloys, equilibrium pressure in the BCC plateau at $30^{\circ} \mathrm{C}$ and $60^{\circ} \mathrm{C}$ were used to estimate the $\Delta H_{\mathrm{h}}$ and entropy $(\Delta S)$ by the equation:

$$
\Delta G=\Delta H_{\mathrm{h}}-T \Delta S=R T \ln P
$$

where $R$ is the ideal gas constant and $T$ is the absolute temperature. Results of these calculations are listed in Table 4. The values may not be accurate and can only be used for comparison among these alloys. As the Ni-content in the design increases, both $\Delta H_{\mathrm{h}}$ and $\Delta S$ decrease first and then increase. The decrease in $\Delta H_{\mathrm{h}}$ of the first three alloys (P17, $\mathrm{P} 22$ and $\left.\mathrm{P} 23\right)$ is due to the reduction in the TiNi phase abundance reducing the proximity effects from the catalytic phases [45]. Further increase in $\Delta H_{\mathrm{h}}$ is due to the shrinking unit cell volume in BCC phase [46]. $\Delta S$ is an indication of how far the MH system is from a perfect, ordered state. The theoretical value of $\Delta S$ is the entropy of hydrogen gas, which is close to $-135 \mathrm{~J} \mathrm{~mol}^{-1} \mathrm{~K}^{-1}$. Alloy $\mathrm{P} 23$ shows the lowest $\Delta H_{h}$ and $\Delta S$, and this indicates that it has the least interaction between the main storage phase and the catalytic phase, acting as a single BCC phase $\mathrm{MH}$ alloy. 


\subsection{Electrochemical Measurement}

The electrochemical discharge capacity of each alloy was measured in a flooded-cell configuration against a partially pre-charged $\mathrm{Ni}(\mathrm{OH})_{2}$ positive electrode. No alkaline pretreatment was applied before the half-cell measurement. For the activation behavior study, each sample electrode was charged at a constant current density of $50 \mathrm{~mA} \cdot \mathrm{g}^{-1}$ for $10 \mathrm{~h}$ and then discharged at a current density of $50 \mathrm{~mA} \cdot \mathrm{g}^{-1}$ followed by two pulls at $12 \mathrm{~mA} \cdot \mathrm{g}^{-1}$ and $4 \mathrm{~mA} \cdot \mathrm{g}^{-1}$. The results of the low-rate (full) capacity and the $\mathrm{HRD}_{50}$ (defined as the ratio in capacities obtained between $50 \mathrm{~mA} \cdot \mathrm{g}^{-1}$ and $4 \mathrm{~mA} \cdot \mathrm{g}^{-1}$ ) for the first thirteen cycles are plotted in Figure 7. From the comparison, it is easy to see that the activation in low-rate capacity is similar for all alloys (Figure 7a), but the activation in HRD (more related to surface oxidation and pulverization) is easier in alloys with lower Ni-content and becomes more difficult with the increase in Ni-content (Figure 7b). Capacities measured at the 4th cycle are listed in Table 5 together with other important electrochemical and magnetic properties of the alloys in this study. The capacities measured at the 4th cycle are also plotted in Figure 8 with the gaseous phase capacity converted to a theoretical electrochemical capacity by

$$
1 \mathrm{wt} \% \text { of } \mathrm{H}_{2}=268 \mathrm{mAh} \cdot \mathrm{g}^{-1}
$$

As the Ni-content in the design increases, both capacities measured at $50 \mathrm{~mA} \cdot \mathrm{g}^{-1}$ and $4 \mathrm{~mA} \cdot \mathrm{g}^{-1}$ rates decrease monotonically, which is similar to the decrease in the maximum storage capacities measured in the gaseous phase. In a conventional MH alloy, the electrochemical capacities measured at different rates fall between the boundaries set by the equivalent maximum and reversible hydrogen storage capacities [29,47-50]. In the current study, the electrochemical capacities drop below the lower bound set by the gaseous phase reversible capacity for alloys P24-P28. It is due to the relatively high equilibrium pressure at room temperature (RT) of these alloys $(>0.6 \mathrm{MPa})$ preventing a full charge under the open flooded half-cell configuration. The electrochemical discharge capacities of these alloys should be higher in a sealed cell where the cell pressure can be kept as high as $2.8 \mathrm{MPa}$.

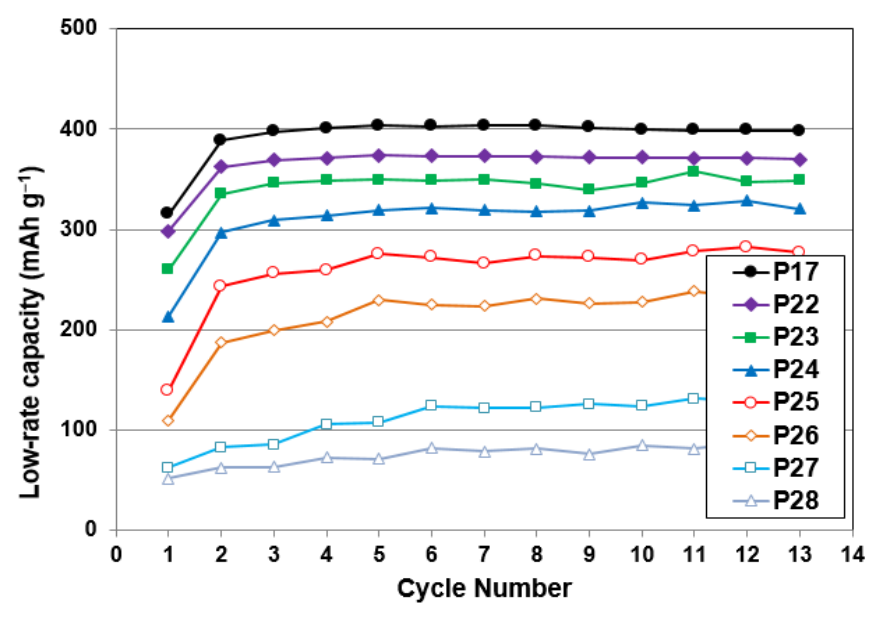

(a)

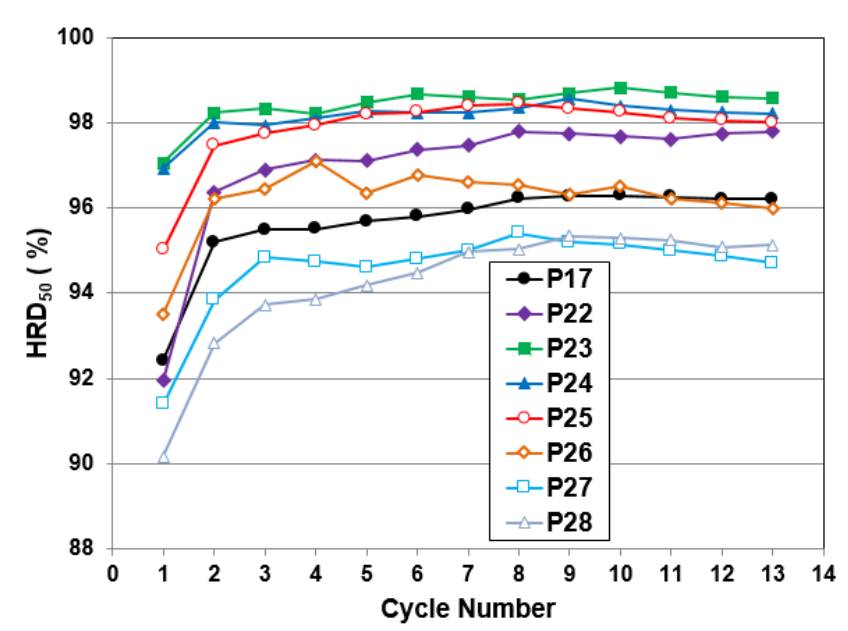

(b)

Figure 7. Activation behavior for the first 13 cycles of (a) low-rate capacity and (b) HRD 50 (ratio of capacities at $50 \mathrm{~mA} \cdot \mathrm{g}^{-1}$ and $4 \mathrm{~mA} \cdot \mathrm{g}^{-1}$ discharge rates). 
Table 5. Summary of electrochemical and magnetic properties. High-rate dischargeability (HRD) 200 is the ratio of capacities measured at $200 \mathrm{~mA} \cdot \mathrm{g}^{-1}$ and $4 \mathrm{~mA} \cdot \mathrm{g}^{-1}$. $\mathrm{RT}$ : room temperature.

\begin{tabular}{|c|c|c|c|c|c|c|c|c|c|}
\hline $\begin{array}{c}\text { Alloy } \\
\text { No. }\end{array}$ & $\begin{array}{c}\text { 4th cycle } \\
\text { capacity @ } \\
50 \mathrm{~mA} \cdot \mathrm{g}^{-1}\end{array}$ & $\begin{array}{c}\text { 4th cycle } \\
\text { capacity @ } \\
4 \mathrm{~mA} \cdot \mathrm{g}^{-1}\end{array}$ & HRD $_{200}$ & $\begin{array}{c}\text { Activation } \\
\text { cycle to reach } \\
\text { maximum }\end{array}$ & $\begin{array}{c}\text { Diffusion } \\
\text { coefficient, } D \\
\text { @RT }\end{array}$ & $\begin{array}{c}\text { Exchange } \\
\text { current } I_{0} \\
@ \text { RT }\end{array}$ & Ms & $H_{1 / 2}$ & $\begin{array}{c}\text { Open } \\
\text { circuit } \\
\text { voltage }\end{array}$ \\
\hline & $\left(\mathrm{mAh} \cdot \mathrm{g}^{-1}\right)$ & $\left(\mathrm{mAh} \cdot \mathrm{g}^{-1}\right)$ & & capacity & $\left(10^{-10} \cdot \mathrm{cm}^{2} \cdot \mathrm{s}^{-1}\right)$ & $\left(\mathrm{mA} \cdot \mathrm{g}^{-1}\right)$ & $\left(\mathrm{emu} \cdot \mathrm{g}^{-1}\right)$ & (kOe) & (V) \\
\hline P17 & 382.7 & 400.7 & 0.815 & 6 & 1.69 & 36.5 & 0.39 & 0.11 & 1.302 \\
\hline $\mathrm{P} 22$ & 360.4 & 371.0 & 0.873 & 5 & 1.67 & 25.2 & 1.40 & 0.11 & 1.306 \\
\hline $\mathrm{P} 23$ & 342.6 & 348.8 & 0.920 & 5 & 2.95 & 25.5 & 0.62 & 0.11 & 1.326 \\
\hline P24 & 308.1 & 314.1 & 0.939 & 6 & 2.85 & 20.0 & 0.92 & 0.10 & 1.330 \\
\hline $\mathrm{P} 25$ & 253.9 & 259.2 & 0.965 & 5 & 1.58 & 18.9 & 1.03 & 0.10 & 1.312 \\
\hline P26 & 201.6 & 207.7 & 0.913 & 5 & 1.22 & 12.8 & 1.81 & 0.11 & 1.288 \\
\hline P27 & 100.1 & 105.6 & - & 6 & 1.39 & 12.3 & 1.42 & 0.14 & 1.264 \\
\hline P28 & 68.0 & 72.4 & - & 6 & 1.46 & 16.3 & 1.40 & 0.12 & 1.332 \\
\hline
\end{tabular}

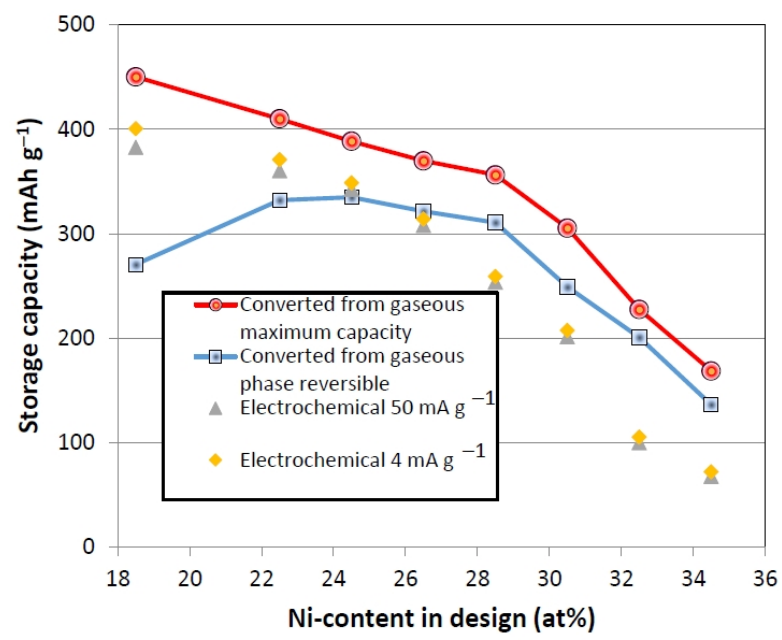

Figure 8. Plot of gaseous phase and electrochemical storage capacities as functions of Ni-content in design.

Half-cell HRD 200 of each alloy, defined as the ratio of discharge capacities measured at $200 \mathrm{~mA} \cdot \mathrm{g}^{-1}$ and $4 \mathrm{~mA} \cdot \mathrm{g}^{-1}$, is listed in Table 5. As the Ni-content in the alloy increases, HRD200 increases in the beginning, maximizes at alloy P25 and then decreases. When the discharge capacities at different discharge rates are compared against a commercially available standard $\mathrm{AB}_{5} \mathrm{MH}$ alloy with a $\mathrm{HRD}_{200}$ of 0.958 (Figure 9), only alloy P25 shows better rate-capability, but its capacities are too low. We find that although BCC-TiNi-Laves MH alloys have higher discharge capacities at a lower rate $\left(<200 \mathrm{~mA} \cdot \mathrm{g}^{-1}\right)$, their high-rate capacities are not as good as in conventional $\mathrm{AB}_{5} \mathrm{MH}$ alloys.

In order to further study the inferior HRD capability in BCC-TiNi-Laves $\mathrm{MH}$ alloys compared to $\mathrm{AB}_{5}$ MH alloys, both the bulk diffusion coefficient $(D)$ and the surface exchange current $\left(I_{\mathrm{o}}\right)$ of the alloys under the current study were measured electrochemically. The details of both parameters' measurements were previously reported [51], and the values are listed in Table 5. As the Ni-content in design increases, the $D$ value increases and then decreases, while $I_{\mathrm{o}}$ decreases. The evolution of the HRD is more similar to the trend in $D$ than in $I_{\mathrm{o}}$, and therefore we conclude that the high-rate performance in this series of 
alloys is more related to the bulk diffusion than to the surface reaction. The increase in $D$ initially is due to the shrinking unit cells for BCC, TiNi, and C14 phases (Table 2). In a comparison study, C15 phase shows faster hydrogen bulk diffusion than $\mathrm{C} 14$ phase [52]; therefore, the subsequent decrease in $D$ with higher Ni-content is most likely related to the formation of $\sigma$-VNi phase. CALPHAD thermodynamic calculations show that hydrogen permeability is reduced with higher Ni-content in V-Ni alloys [53]. Compared to the $D$ value from a typical $\mathrm{AB}_{5} \mathrm{MH}$ alloy $\left(2.55 \times 10^{-10} \mathrm{~cm}^{2} \cdot \mathrm{s}^{-1}[54]\right)$, alloys P23 and P24 have faster bulk hydrogen diffusion. The reason the BCC-TiNi-Laves alloys have lower HRDs despite better bulk diffusion is because of their relatively low $I_{0}$ values (Table 5) compared to $\mathrm{AB}_{5} \mathrm{MH}$ alloy (43.2 $\left.\mathrm{mA} \cdot \mathrm{g}^{-1},[54]\right)$. When the abundances of the catalytic secondary phases (Laves and TiNi) are plotted against the $I_{\mathrm{o}}$ values as shown in Figure 10, it is clear that while Laves phases (C14 and C15) appear beneficial, TiNi phase appears detrimental to the surface electrochemical reaction. Similar findings regarding TiNi phase hindering the HRD performance of Laves phase based $\mathrm{AB}_{2} \mathrm{MH}$ alloys were reported before [55].

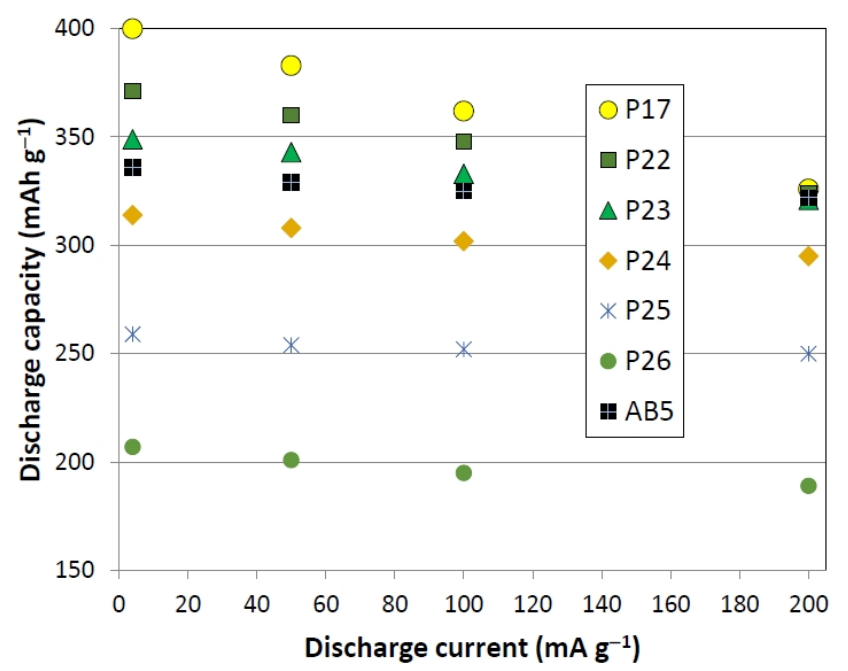

Figure 9. Rate-dependent discharge capacity for alloys P17, P22-P26 and a commercially available $\mathrm{AB} 5 \mathrm{MH}$ alloy.

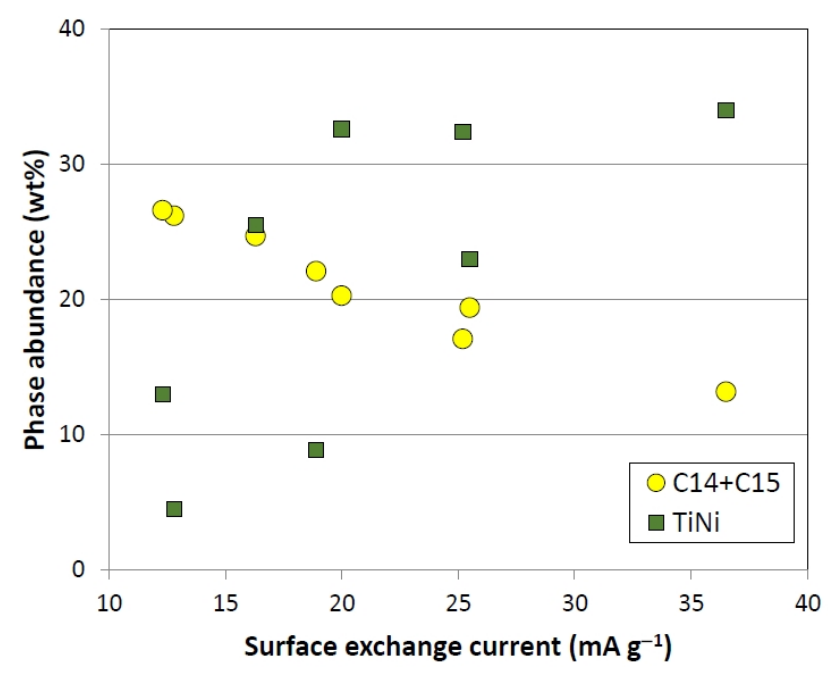

Figure 10. Plots of Laves $(\mathrm{C} 14+\mathrm{C} 15)$ and TiNi phase abundances $v$ s. the surface exchange current. 
The lower surface reaction currents measured in the current series of alloys were further investigated by magnetic susceptibility measurement. Details of the background and the experimental method are published in [56]. Metallic Ni is an active catalyst for the water splitting and recombination reactions that contribute to the $I_{\mathrm{o}}$ in this electrochemical system, and this technique allows us to obtain the saturated magnetic susceptibility $(M \mathrm{~s})$, a quantification of the amount of surface metallic $\mathrm{Ni}$ (the product of preferential oxidation), and the magnetic field strength at one-half of the $M_{\mathrm{s}}$ value $\left(H_{1 / 2}\right)$, a measure of the average reciprocal number of $\mathrm{Ni}$ atoms in a metallic cluster. $M_{\mathrm{S}}$ and $H_{1 / 2}$ values for the alloys in this study are listed in Table 5. While the $H_{1 / 2}$ values of these alloys are very similar, the trend of $M_{\mathrm{s}}$ values with the increase in Ni-content is not obvious. When these values are compared to values from an $\mathrm{AB}_{5} \mathrm{MH}$ alloy $\left(M_{\mathrm{S}}=0.434 \mathrm{emu} \cdot \mathrm{g}^{-1}\right.$ and $H_{1 / 2}=0.17 \mathrm{kOe}$ [54]), we find that all alloys except $\mathrm{P} 17$ have higher $M_{\mathrm{S}}$ values. These BCC-TiNi-Laves alloys have higher weight percentage of metallic Ni in their activated surfaces and should have better HRD [57]. The reason for the lower $I_{0}$ values in this current series of alloys may be due to their relatively larger Ni cluster sizes, resulting in less surface area, which is indicated by smaller $H_{1 / 2}$ values. Systematic transmission electron microscope work is necessary here to continue the investigation of the metallic inclusions, particularly their size and shape, embedded in the activated surface oxide layer of these alloys.

The open circuit voltage (OCV) of the electrochemical cells comprising a negative electrode from each alloy and a $\mathrm{Ni}(\mathrm{OH})_{2} / \mathrm{NiOOH}$ positive electrode is listed in Table 5 . OCV is important for the power density of the cell and is usually proportional to the logarithm of equilibrium pressure, typical of most $\mathrm{MH}$ alloys. In the previous study in a series of BCC-C14 alloys, the OCV is inversely proportional to the desorption equilibrium pressure [26]. In the current series of alloys, the plateau pressure increases with the increase in Ni-content, but the OCV first increases and then decreases except for the last alloy P28, which shows very small discharge capacity due to insufficient charging in the open-air configuration. The evolution of OCV in this study is similar to the trends in HRD and maximizes with alloy P24.

\section{Conclusions}

The Ni-content in a base alloy, P17, was increased with the intention to improve the electrochemical high-rate performance in the negative electrode active material for $(\mathrm{Ni} / \mathrm{MH})$ batteries. Although the HRD improved with the increase in Ni-content at the expense of $\mathrm{V}$, the discharge capacity was deteriorated. An alloy, P23, with a composition of $\mathrm{Ti}_{15.6} \mathrm{Zr}_{2.1} \mathrm{~V}_{36} \mathrm{Cr}_{11.2} \mathrm{Mn}_{6.9} \mathrm{Co}_{1.4} \mathrm{Ni}_{26.5} \mathrm{Al}_{0.3}$ shows a good balance between capacity and high-rate capability. The increase in Ni-content shifts the Laves phase from C14 into $\mathrm{C} 15$ because of the increase in the average electron density in the phase. The increase in Ni-content also promotes a new $\sigma$-VNi phase, which has a similar hydrogen-metal bond strength as the main BCC phase. The new phase is associated with reduced bulk diffusion of hydrogen. Further improvement in high-rate capability in this family of alloys should maintain the Ni-level at 22.5 at $\%$ to 26.5 at $\%$ and increase the content of other C14-promoters, such as $\mathrm{Zr}$ and $\mathrm{Hf}$.

\section{Acknowledgments}

This work is financially supported by Advanced Research Projects Agency-Energy (ARPA-E) under the robust affordable next generation EV-storage (RANGE) program (DE-AR0000386). The authors thank 
these colleagues for technical assistance: Simon Ng, Shuli Yan, Shiuan Chang (Wayne State University), Michael A. Fetcenko, Baoquan Huang, Tiejun Meng, David Pawlik, Allen Chan, Ryan J. Blankenship and $\mathrm{Su}$ Cronogue (BASF-Ovonic).

\section{Conflicts of Interest}

The authors declare no conflict of interest.

\section{References}

1. Iba, H.; Akiba, E. Hydrogen absorption and microstructure in BCC alloys with C14-type Lave phase. J. Jpn. Inst. Met. Mater. 1994, 58, 1225-1232.

2. Akiba, E.; Iba, H. Hydrogen absorption by Laves phase related BCC solid solution. Intermetallics 1998, 6, 461-470.

3. Enomoto, M. The Cr-Ti-V system. J. Phase Equilibria 1992, 13, 195-200.

4. Inoue, H.; Arai, S.; Iwakura, C. Crystallographic and electrochemical characterization of $\mathrm{TiV}_{4-x} \mathrm{Ni}_{x}$ alloys for nickel-metal hydride batteries. Electrochim. Acta 1996, 41, 937-939.

5. Yu, X.; Wu, Z.; Xia, B.; Xu, N. A Ti-V-based bec phase alloy for use as metal hydride electrode with high discharge capacity. J. Chem. Phys. 2004, 121, 987-990.

6. Young, K.-H.; Ouchi, T.; Huang, B.; Nei, J. Structure, hydrogen storage, and electrochemical properties of body-centered-cubic $\mathrm{Ti}_{40} \mathrm{~V}_{30} \mathrm{Cr}_{15} \mathrm{Mn}_{13} X_{2}$ alloys ( $X=\mathrm{B}, \mathrm{Si}, \mathrm{Mn}, \mathrm{Ni}, \mathrm{Zr}, \mathrm{Nb}, \mathrm{Mo}$, and La). Batteries 2015, 1, 74-90, doi:10.3390/batteries1010074.

7. Chen, N.; Li, R.; Zhu, Y.; Liu, Y.; Pan, H. Electrochemical hydrogenation and dehydrogenation mechanisms of the Ti-V base multiphase hydrogen storage electrode alloy. Acta Metall. Sin. 2004, 40, 1200-1204.

8. Iba, H.; Akiba, E. The relation between microstructure and hydrogen absorbing property in Laves phase-solid solution multiphase alloys. J. Alloy. Compd. 1995, 231, 508-512.

9. Rönnebro, E.; Noréus, D.; Sakai, T.; Tsukahara, M. Structural studies of a new Laves phase alloy (Hf,Ti)(Ni,V)2 and its very stable hydride. J. Alloy. Compd. 1995, 231, 90-94.

10. Tsukahara, M.; Takahashi, K.; Mishima, T.; Isomura, A.; Sakai, T. V-based solid solution alloys with Laves phase network: Hydrogen absorption properties and microstructure. J. Alloy. Compd. 1996, 236, 151-155.

11. Qiu, S.; Chu, H.; Zhang, Y.; Sun, D.; Song, X.; Sun, L.; Fen, X. Electrochemical kinetics and its temperature dependence behaviors of $\mathrm{Ti}_{0.17} \mathrm{Zr}_{0.08} \mathrm{~V}_{0.35} \mathrm{Cr}_{0.10} \mathrm{Ni} 0.30$ alloy electrode. J. Alloy. Compd. 2009, 471, 453-456.

12. Iba, H.; Akiba, E. Hydrogen absorption and modulated structure in Ti-V-Mn alloys. J. Alloy. Compd. 1997, 253-254, 21-24.

13. Shashikala, K.; Banerjee, S.; Kumar, A.; Pai, M.R.; Pillai, C.G.S. Improvement of hydrogen storage properties of TiCrV alloy by Zr substitution for Ti. Int. J. Hydrog. Energy 2009, 34, 6684-6689.

14. Yang, X.; Li, J.; Zhang, T.; Hu, R.; Xue, X.; Fu, H. Role of defect structure on hydrogenation properties of $\mathrm{Zr}_{0.9} \mathrm{Ti}_{0.1} \mathrm{~V}_{2}$ alloy. Int. J. Hydrog. Energy 2011, 36, 9318-9323. 
15. Huot, J.; Akiba, E.; Ogura, T.; Ishido, Y. Crystal structure, phase abundance and electrode performance of Laves phase compounds ( $\mathrm{Zr}, \mathrm{A}) \mathrm{V}_{0.5} \mathrm{Ni}_{1.1} \mathrm{Mn}_{0.2} \mathrm{Fe}_{0.2}$ (A $\equiv \mathrm{Ti}, \mathrm{Nb}$ or Hf). J. Alloy. Compd. 1995, 218, 101-109.

16. Qiu, S.-J.; Chu, H.-L.; Zhang, J.; Zhang, Y.; Sun, L.-X.; Xu, F.; Sun, D.-L.; Ouyang, L.-Z.; Zhu, M.; Grolier, J.-P.E.; et al. Effect of La partial substitution for $\mathrm{Zr}$ on the structural and electrochemical properties of $\mathrm{Ti}_{0.17} \mathrm{Zr}_{0.08-x} \mathrm{La}_{x} \mathrm{~V}_{0.35} \mathrm{Cr}_{0.1} \mathrm{Ni}_{0.3}(x=0-0.04)$ electrode alloys. Int. J. Hydrog. Energy 2009, 34, 7246-7252.

17. Huang, Z.; Cuevas, F.; Liu, X.; Jiang, L.; Wang, S.; Latroche, M.; Du, J. Effects of Si addition on the microstructure and the hydrogen storage properties of $\mathrm{Ti}_{26.5} \mathrm{~V}_{45} \mathrm{Fe}_{8.5} \mathrm{Cr}_{20} \mathrm{Ce}_{0.5}$ BCC solid solution alloys. Int. J. Hydrog. Energy 2009, 34, 9385-9392.

18. Kamegawa, A.; Shirasaki, K.; Tamura, T.; Kuriiwa, T.; Takamura, H.; Okada, M. Crystal structure and protium absorption properties of Ti-Cr-X alloys. Mater. Trans. 2002, 43, 470-473.

19. Liu, Y.; Zhang, S.; Li, R.; Gao, M.; Zhong, K.; Miao, H.; Pen, H. Electrochemical performances of the Pd-added Ti-V-based hydrogen storage alloys. Int. J. Hydrog. Energy 2008, 33, 728-734.

20. Kuriiwa, T.; Tamura, T.; Amemiya, T.; Fuda, T.; Kamegawa, A.; Takamura, H.; Okada, M. New V-based alloys with high protium absorption and desorption capacity. J. Alloy. Compd. 1999, 293-295, 433-436.

21. Yu, J.; Liu, B.; Cho, K.; Lee, J. The effects of partial substitution of Mn by Cr on the electrochemical cycle life of Ti-Zr-V-Mn-Ni alloy electrodes of a Ni/MH battery. J. Alloy. Compd. 1998, 278, 283-290.

22. Lee, H.-H.; Lee, K.-Y.; Lee, J.-Y. The Ti-based metal hydride electrode for Ni-MH rechargeable batteries. J. Alloy. Compd. 1996, 239, 63-70.

23. Kim, J.; Paik, C.; Cho, W.; Cho, B.; Yun, K.; Kim, S. Corrosion behaviour of $\mathrm{Zr}_{1-x} \mathrm{Ti}_{x} \mathrm{~V}_{0.6} \mathrm{Ni}_{1.2} \mathrm{M}_{0.2}$ $(\mathrm{M}=\mathrm{Ni}, \mathrm{Cr}, \mathrm{Mn}) \mathrm{AB}_{2}$-type metal hydride alloys in alkaline solution. J. Power Sources 1998, 75 , 1-8.

24. Young, K.; Wong, D.; Wang, L. Effect of Ti/Cr content on the microstructures and hydrogen storage properties of Laves phase-related body-centered-cubic solid solution alloys. J. Alloy. Compd. 2015, 622, 885-893.

25. Young, K.; Ouchi, T.; Nei, J.; Wang, L. Annealing effects on Laves phase-related body-centered-cubic solid solution metal hydride alloys. J. Alloy. Compd. 2016, 654, 216-225.

26. Young, K.; Ouchi, T.; Nei, J.; Meng, T. Effects of Cr, Zr, V, Mn, Fe, and Co to the hydride properties of Laves phase-related body-centered-cubic solid solution alloys. J. Power Sources $\mathbf{2 0 1 5}$, 281, 164-172.

27. Young, K.; Ouchi, T.; Reichman, B.; Koch, J.; Fetcenko, M.A. Effects of Mo additive on the structure and electrochemical properties of low-temperature $\mathrm{AB}_{5}$ metal hydride alloys. J. Alloy. Compd. 2011, 509, 3995-4001.

28. Chai, Y.; Zhao, M. Structure and electrochemical properties of $\operatorname{Ti}_{0.25} \mathrm{~V}_{0.35} \mathrm{Cr}_{0.40-x} \mathrm{Ni}_{x}(x=0.05-0.40)$ solid solution alloys. Int. J. Hydrog. Energy 2005, 30, 279-283.

29. Young, K.; Fetcenko, M.A.; Li, F.; Ouchi, T. Structural, thermodynamic, and electrochemical properties of $\mathrm{Ti}_{x} \mathrm{Zr}_{1-x}(\mathrm{VNiCrMnCoAl})_{2} \mathrm{C} 14$ Laves phase alloys. J. Alloy. Compd. 2008, 464, 238-247. 
30. Young, K.; Ouchi, T.; Fetcenko, M.A. Roles of Ni, Cr, Mn, Sn, Co, and Al in C14 Laves phase alloys for NiMH battery application. J. Alloy. Compd. 2009, 476, 774-781.

31. Li, R.; Pan, H.; Gao, M.; Zhu, Y.; Liu, Y.; Jin, Q.; Lei, Y. Structural and electrochemical properties of hydrogen storage alloys $\mathrm{Ti}_{0.8} \mathrm{Zr}_{0.2} \mathrm{~V}_{2.7} \mathrm{Mn}_{0.5} \mathrm{Cr}_{0.8} \mathrm{Ni}_{x}(x=1.50-2.25)$. J. Alloy. Compd. 2004, 373, 223-230.

32. Pan, H.; Li, R.; Gao, M.; Liu, Y.; Lei, Y.; Wang, Q. Effects of Ni on the structural and electrochemical properties of Ti-V-based hydrogen storage alloys. Int. J. Hydrog. Energy 2006, 31, 1188-1195.

33. Pearson, W.; Christian, J. The structure of the $\sigma$ phase in vanadium-nickel alloys. Acta Crystallogr. 1952, 5, 157-162.

34. Massalski, T.; Okamoto, H.; Subramanian, P.; Kacprzak, L. Binary Alloy Phase Diagram, 2nd ed.; ASM International: Materials Park: Ohio, USA, 1990; p. 2880.

35. Kodentzov, A.A.; Dunaev, S.F.; Slusarenko, E.M. Determination of the phase diagram of the V-Ni-Cr system using diffusion couples and equilibrated alloys. J. Less Common Met. 1987, 135, 15-24.

36. Yan, Y.; Chen, Y.; Liang, H.; Zhou, X.; Wu, C.; Tao, M.; Pang, L. Hydrogen storage properties of V-Ti-Cr-Fe alloys. J. Alloy. Compd. 2008, 454, 427-431.

37. Young, K.; Nei, J.; Wong, D.; Wang, L. Structural, hydrogen storage, and electrochemical properties of Laves-phase related body-centered-cubic solid solution metal hydride alloys. Int. J. Hydrog. Energy 2014, 39, 21489-21499.

38. Johnston, R.L.; Hoffmann, R. Structure-bonding relationships in the Laves phases. Z. Anorg. Allg. Chem. 1992, 616, 105-120.

39. Nei, J.; Young, K.; Salley, S.O.; Ng, K. Determination of C14/C15 phase abundance in Laves phase alloys. Mater. Chem. Phys. 2012, 136, 520-527.

40. Young, K.; Fetcenko, M.A.; Li, F.; Ouchi, T.; Koch, J. Effect of vanadium substitution in C14 Laves phase alloys for NiMH battery application. J. Alloy. Compd. 2009, 468, 482-492.

41. Young, K.; Ouchi, T.; Huang, B.; Reichman, B.; Fetcenko, M.A. Effect of molybdenum content on structure, gaseous storage, and electrochemical properties of C14-predominant $\mathrm{AB}_{2}$ metal hydride alloys. J. Power Sources 2011, 196, 8815-8821.

42. Young, K. Metal Hydrides. In Elsevier Reference Module in Chemistry, Molecular Sciences and Chemical Engineering; Elsevier B.V.: Waltham, MA, USA, 2013.

43. Griessen, R.; Riesterer, T. Heat of Formation Models. In Hydrogen in Intermetallic Compounds I; Schlapbach, L., Ed.; Springer-Verlag: Berlin, Germany, 1988; p. 273.

44. Balasubramaniam, R. Hysteresis in metal-hydrogen systems. J. Alloy. Compd. 1997, 253-254, 203-206.

45. Wong, D.; Young, K.; Nei, J.; Wang, L.; Ng, K. Effects of Nd-addition on the structural, hydrogen storage, and electrochemical properties of $\mathrm{C} 14$ metal hydride alloys. J. Alloy. Compd. 2015, 647, 507-518.

46. Nakano, H.; Wakao, S. Substitution effect of elements in Zr-based alloys with Laves phase for nickel-hydride battery. J. Alloy. Compd. 1995, 231, 587-593.

47. Nei, J.; Young, K.; Sally, S.O.; Ng, K. Effects of annealing on $\mathrm{Zr}_{8} \mathrm{Ni}_{19} \mathrm{X}_{2}$ (X= Ni, Mg, Al, Sc, V, $\mathrm{Mn}, \mathrm{Co}, \mathrm{Sn}, \mathrm{La}$, and Hf): Hydrogen storage and electrochemical properties. Int. J. Hydrog. Energy 2012, 37, 8418-8427. 
48. Sun, D.; Jiang, J.; Lei, Y.; Liu, W.; Wu, J.; Wang, Q.; Yang, G. Effects of measurement factor on electrochemical capacity of some hydrogen storage alloys. Mater. Sci. Eng. B 1995, 30, 19-22.

49. Young, K.; Nei, J.; Huang, B.; Ouchi, T.; Fetcenko, M.A. Studies of Ti1.5Zr5.5 $\mathrm{V}_{0.5}\left(\mathrm{M}_{x} \mathrm{Ni}_{1-x}\right)_{9.5}$ $(\mathrm{M}=\mathrm{Cr}, \mathrm{Mn}, \mathrm{Fe}, \mathrm{Co}, \mathrm{Cu}, \mathrm{Al})$ : Part 2. Hydrogen storage and electrochemical properties. J. Alloy. Compd. 2010, 501, 245-254.

50. Young, K.; Chao, B.; Huang, B.; Nei, J. Studies on the hydrogen storage characteristic of $\mathrm{La}_{1-x} \mathrm{Ce}_{x}(\mathrm{NiCoMnAlCuSiZr}) 5.7$ with a B2 secondary phase. J. Alloy. Compd. 2014, 585, 760-770.

51. Li, F.; Young, K.; Ouchi, T.; Fetcenko, M.A. Annealing effects on structural and electrochemical properties of (LaPrNdZr) ${ }_{0.83} \mathrm{Mg}_{0.17}(\mathrm{NiCoAlMn})_{3.3}$ alloy. J. Alloy. Compd. 2009, 471, 371-377.

52. Young, K.; Ouchi, T.; Huang, B.; Chao, B.; Fetcenko, M.A.; Bendersky, L.A.; Wang, K.; Chiu, C. The correlation of $\mathrm{C} 14 / \mathrm{C} 15$ phase abundance and electrochemical properties in the $\mathrm{AB}_{2}$ alloys. J. Alloy. Compd. 2010, 506, 841-848.

53. Shim, J.H.; Ko, W.S.; Kim, K.H.; Lee, H.S.; Lee, Y.S.; Suh, J.Y.; Choa, Y.W.; Lee, B.-J. Prediction of hydrogen permeability in V-Al and V-Ni alloys. J. Membr. Sci. 2014, 430, 234-241.

54. Young, K.; Nei, J. The current status of hydrogen storage alloy development for electrochemical applications. Materials 2013, 6, 4574-4608.

55. Young, K.; Nei, J.; Ouchi, T.; Fetcenko, M.A. Phase abundances in $\mathrm{AB}_{2}$ metal hydride alloys and their correlations to various properties. J. Alloy. Compd. 2011, 509, 2277-2284.

56. Young, K.; Wong, D.; Wang, L.; Nei, J.; Ouchi, T.; Yasuoka, S. Mn in misch-metal based superlattice metal hydride alloy_Part 1 structural, hydrogen storage and electrochemical properties. J. Power Sources 2015, 277, 426-432.

57. Young, K.; Huang, B.; Regmi, R.K.; Lawes, G.; Liu, Y. Comparisons of metallic clusters imbedded in the surface oxide of $\mathrm{AB}_{2}, \mathrm{AB}_{5}$, and $\mathrm{A}_{2} \mathrm{~B}_{7}$ alloys. J. Alloy. Compd. 2010, 506, 831-840.

(C) 2015 by the authors; licensee MDPI, Basel, Switzerland. This article is an open access article distributed under the terms and conditions of the Creative Commons Attribution license (http://creativecommons.org/licenses/by/4.0/). 